\title{
Differential locomotor and predatory strategies of Gondwanan and derived Laurasian dromaeosaurids (Dinosauria, Theropoda, Paraves): Inferences from morphometric and comparative anatomical studies
}

\section{Federico A. Gianechini ${ }^{1}$ (D) \\ ${ }^{1}$ Instituto Multidisciplinario de Investigaciones Biológicas (IMIBIO), CONICET-Universidad Nacional de San Luis, Ciudad de San Luis, Argentina \\ ${ }^{2}$ Instituto de Ecorregiones Andinas (INECOA), Universidad Nacional de Jujuy- CONICET, IdGyM, San Salvador de Jujuy, Argentina \\ ${ }^{3}$ Instituto de Investigación en Paleobiologia y Geología (IIPG), CONICET-Universidad Nacional de Río Negro, General Roca, Argentina}

\section{Correspondence}

Federico A. Gianechini, Instituto Multidisciplinario de Investigaciones Biológicas (IMIBIO), CONICET-Universidad Nacional de San Luis, Ciudad de San Luis, San Luis, Argentina.

Email: fgianechini@conicet.gov.ar

\section{Funding information}

Agencia Nacional de Promoción Científica y Tecnológica, Grant/Award Number: PICT 2014-1449; Secretaría de Ciencia y Tecnología UNSL, Grant/Award Number: PROICO 2-0618; The Jurassic Foundation; American Museum of Natural History; CONICET

\section{Marcos D. Ercoli ${ }^{2}$ (D) | Ignacio Díaz-Martínez ${ }^{3}$}


and phalanges, possibly allowed eudromaeosaurs to exert a great gripping strength and hunt large prey. Conversely, the longer and slender subarctometatarsus, and less well-marked hinge joints of unenlagiines possibly gave them greater cursorial capacities. Additionally, the longer second phalanx of digit II allowed unenlagiines fast movements of this digit to hunt smaller and elusive prey. Thus, the distinctive morphological evolutionary pathways of these two dromaeosaurid clades seem to have been influenced by the particular locomotor and predatory specializations that characterized each of these lineages.

\section{KEYWORDS}

Dromaeosauridae, functional morphology, life habit, Paraves, Unenlagiinae

\section{1 | INTRODUCTION}

Unenlagiinae is a clade of Gondwanan paravians, first recognized by Bonaparte (1999), which has been generally considered a subfamily of dromaeosaurids since the phylogenetic analysis of Makovicky et al. (2005). However, recent studies have challenged the dromaeosaurian affinities of unenlagiines and proposed instead an alternative phylogenetic hypothesis locating these theropods within the stem of Avialae (Agnolín and Novas, 2011, 2013). Despite and beyond the ongoing controversy about the relationships of unenlagiines, there are many shared morphological features between unenlagiines and other dromaeosaurids. One of these shared traits is the presence of a modified pedal digit II, with a hyperextensible phalanx II-2 and a hypertrophied sickle-shaped claw. The peculiar form of this digit has led many researchers to propose multiple interpretations about its possible function (e.g. Colbert and Russell, 1969; Ostrom, 1969; Manning et al. 2006; Senter, 2009; Fowler et al. 2011). However they all agree that this digit was involved in food procurement, as the main structure implied in the submission and/or the killing of the prey. Nevertheless, these functional interpretations are based mainly on the anatomy of derived Laurasian taxa (Eudromaeosauria, following Longrich and Currie, 2009; Cau et al. 2017; among others) such as Deinonychus, Velociraptor, Saurornitholestes, Achillobator and Dromaeosaurus. In these taxa the phalanges are markedly modified with respect to the plesiomorphic theropod morphology. The digit II of unenlagiines is similarly modified, although there are some anatomical differences from the digit II of eudromaeosaurs.

Moreover, the anatomical differences between unenlagiines and eudromaeosaurs are not limited to those found in this pedal digit, but also in other parts of the hindlimb. The metatarsus also differs between the two groups, since unenlagiines generally have a subarctometatarsalian condition (Novas and Pol, 2005; Currie and Paulina Carabajal, 2012; Brissón Egli et al. 2017; Gianechini et al. 2018), as also reported in microraptorine dromaeosaurids and some basal troodontids (e.g. Xu and Wang, 2000; Xu et al. 2000, 2002, 2008; Xu, 2002; Xu and Norell, 2004; Zheng et al. 2010; Xu and Qin, 2017). By contrast, in eudromaeosaurs, the metatarsus has a structure more similar to the plesiomorphic theropod condition (e.g. Ostrom,
1969; Barsbold, 1983; Norell and Makovicky, 1999; Xu et al. 2010). In the subarctometatarsalian condition, the metapodium has a partially similar morphology to the arctometatarsus, a type of metatarsal morphology observed in some theropod groups, such as tyrannosaurids, ornithomimids and alvarezsaurids. White (2009) pointed out how these morphologies differ, indicating that in the subarctometatarsus the proximal end of the metatarsal III, although constrained, is equally visible in anterior and posterior views (whereas it is completely constrained proximally in the arctometatarsus and not visible). Additionally, in posterior view, the third metatarsal is visible through the entire length of the metatarsus, excluding metatarsals II and IV from buttressing. Several functional hypotheses have been raised regarding the arctometatarsus, most of them linking it with an increase of mechanical efficiency during locomotion (Coombs, 1978; Wilson and Currie, 1985; Holtz, 1994; Snively and Russell, 2003; Snively et al. 2004; White, 2009). The subarctometatarsalian condition could also have been related to enhancement of locomotor efficiency, and some authors consider it as transitional between the plesiomorphic morphology and the arctometatarsalian condition (White, 2009).

In unenlagiines and eudromaeosaurs, the hindlimb, especially the autopodium, is implied in both locomotor and predatory functions. Accordingly, the morphological differences possibly reflect different locomotor and predatory habits. Based on the previous ideas about the functional implications of the subarctometatarsalian and the arctometatarsalian conditions, unenlagiines would have had locomotor capabilities not present in eudromaeosaurs. Such hypotheses have already been mentioned by previous authors (e.g. Fowler et al. 2011), although they have not been evaluated in a quantitative form, at least not for the case of unenlagiines. The goal of the present study was to perform an analysis including both unenlagiines and eudromaeosaurs, and to approach, in a quantitative manner, the morphological differences between these groups. Additionally, exhaustive morphological comparisons between the autopodia of unenlagiines and eudromaeosaurs and taxa of other theropod groups are performed in order to arrive at a conclusion about the possible functions of the autopodium, and the hindlimb in general, in these two dromaeosaurid clades. 


\section{2 | MATERIALS AND METHODS}

In order to evaluate quantitatively how unenlagiines and eudromaeosaurs differ morphologically, a morphometric analysis was performed employing a set of linear measurements of the hindlimb bones of several theropod taxa. A diverse sample of theropod clades was considered, with the aim of covering a wide spectrum of morphologies, proportions and sizes of the hindlimb elements. The sample includes measurements of Herrerasaurus, non-Tetanurae neotheropods, basal tetanurans, and representatives of most coelurosaur clades, including Mesozoic avialans. Data from more recent, albeit extinct groups of birds, i.e. Dinornithiformes, were also considered, as were data from extant taxa representatives of diverse ecomorphs, in which the locomotor habit, mode of feeding, and particular abilities of the foot such as 'grasping', are known. Extant bird taxa considered in the study include mainly ground-dwellers with high cursorial capacities as well as less cursorial or even non-cursorial, raptorial birds with different hunting modes and 'grasping' capacities, as well as perching birds with more arboreal habits, such as passeriforms, which also have 'grasping' abilities (Appendix S1). The measurements considered include the proximodistal lengths of the femur ( $\mathrm{FL})$, tibiotarsus $(\mathrm{TL})$, metatarsus (MtL), and non-ungual pedal phalanges, and the mediolateral width of the metatarsus at midshaft (ML). The MtL measurements were taken for the longest element, typically the metatarsal III. For modern birds, the length of the tarsometatarsus was considered as MtL, due to the complete fusion of the distal tarsals and the metatarsals. The dimension ML refers to the mediolateral diameter of the articulated metatarsals (MTs) II, III and IV at midshaft of these bones.

Most of the measurements were obtained from published datasets (e.g. Holtz, 1994; Karhu and Rautian, 1996; Xu and Wang, 2000; Xu, 2002; Mayr et al. 2007; Zhou et al. 2010; Turner et al. 2011; Lü and Brusatte, 2015; Tsogtbaatar et al. 2017). Other values were measured directly on materials deposited in different collections (Appendix S1). For many taxa with published measurements, ML was not provided by the authors, so in these cases it was estimated from the published photographs of the specimens. For each taxon, we specified from which specimen the measurements were taken, except in some cases where such identification was not provided by the authors who originally published the data. In the case of taxa with published measurements of several specimens, we decided to consider the data of only one of the specimens, specifically the largest one, in order to avoid data from potentially juvenile individuals. We included mainly complete specimens, i.e. those with all the bones of the hindlimb completely preserved, in order to gather all the required measurement data. In some cases, measurements were estimated for bones with only small portions missing, so that our estimates should approximate reliably the real dimensions of the element. Additionally, measurements of some taxa were obtained directly from materials housed in Argentinean repositories, including one specimen of the alvarezsauroid Alnashetri cerropoliciensis (MPCA), specimens of 17 taxa of extant birds (MACN, one specimen by taxon), and one specimen of Struthio camelus (CFA-OR), as specified in Appendix S1.

The length of the pedal ungual phalanges is measured by some authors in a straight line from the proximal end to the distal end of the phalanx, while others measure only the external curvature. In consequence, published lengths of pedal unguals of theropods are not taken according to the same criteria. Therefore, in the absence of a consensus, we did not consider the lengths of unguals in our analyses. The length of the phalanges of digit I is also not included, because in certain taxa of the clades included in the analysis, i.e. ornithomimids, this digit is atrophied or absent.

We performed phylogenetic principal component analysis (phylogenetic PCA or (PPCA); see Revell, 2009, 2012) using these measurements instead of the traditional PCA. The phylogenetic PCA allows the reduction of the original variables to principal components, while taking into account the non-independence among the former due to the phylogenetic relationships between species. In this way, in a phylogenetic PCA the samples are not considered as independent datapoints, an assumption of the traditional PCA and frequently violated due to the phylogenetic relationships between samples (Revell, 2009).

Given that the purpose of these analyses was the study of shape changes between species that cover a wide range of sizes, the phylogenetic PCAs were constructed from size-standardized, Mosimann variables (Mosimann and James, 1979) instead of the original ones. Each Mosimann variable was obtained as the ratio between the original variable and the geometric mean of all variables considered for the corresponding phylogenetic PCA.

From the complete dataset, two phylogenetic PCAs were performed. One of them includes the measurements of the long bones of the hindlimb, i.e. FL, TL, MtL and ML, and the other, the lengths of the non-ungual pedal phalanges. Due to data availability (Appendix S1), the first PPCA included 74 taxa, whereas the second included 32 taxa (Fig. 1). This methodological design resulted in a different taxonomic coverage in each PPCA (in relation to the available data and due to the inability to perform these analyses with missing data), allowing the maximization of the number of morphologies and taxa considered in each analysis.

After the phylogenetic PCA was computed, the phylogenetic relationships between species were projected into bivariate plots of morphospaces, constructing phylomorphospaces (Revell, 2012). The evaluation of the phylogenetic signal on each phylogenetic principal component was made with the $K$ statistic proposed by Blomberg et al. (2003) calculated for each axis. The $K$ statistic provides a measure of the strength of the phylogenetic signal within the data. Values smaller than one indicate a lack of phylogenetic signal, or strong adaptative processes. Values near one are expected if the character evolved following the phylogenetic relationships, under a Brownian motion model. Values greater than one show that phylogenetically close taxa are more similar than expected and they eventually indicate stasis (Blomberg et al. 2003; Losos, 2008). 


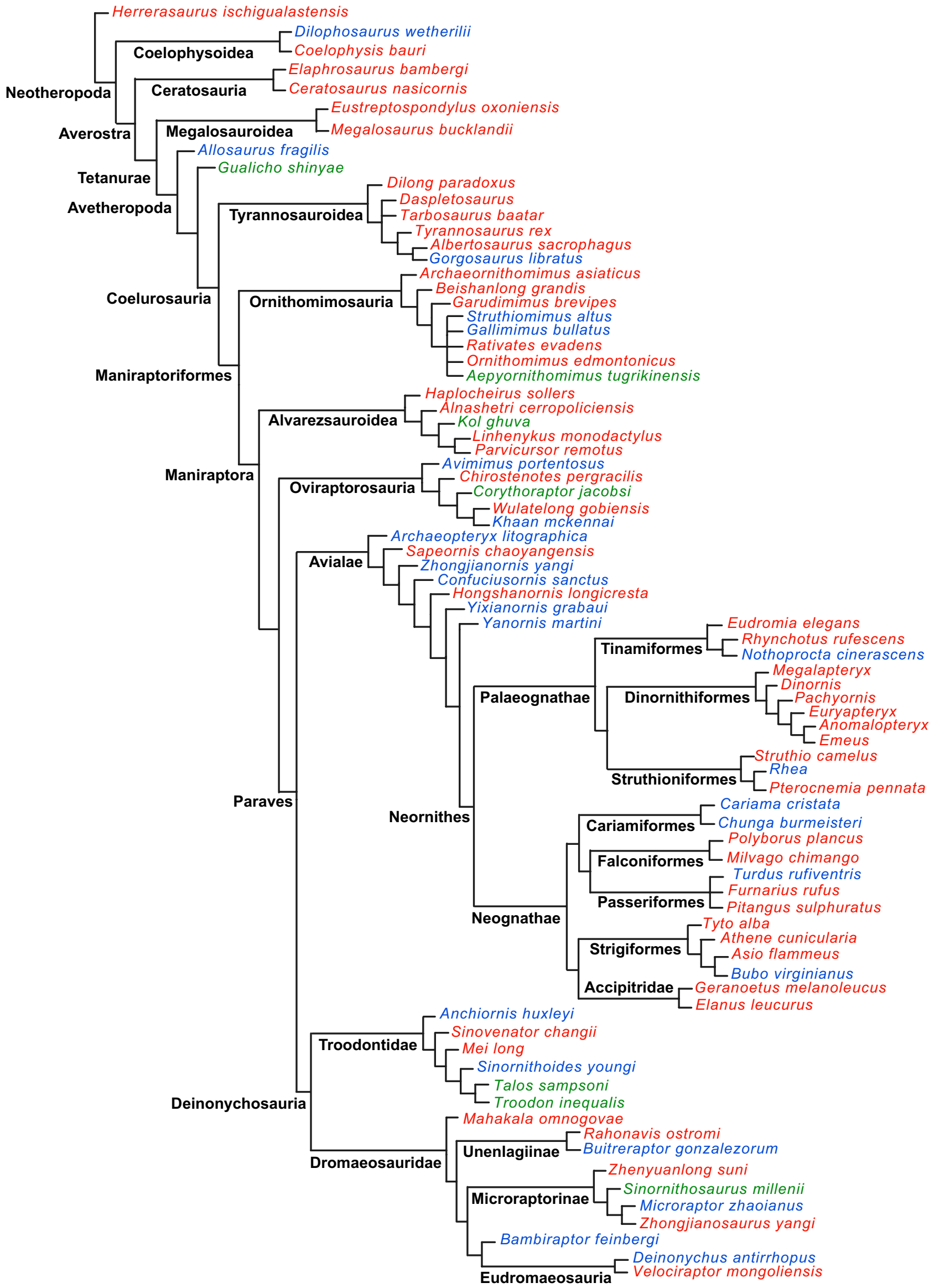


FIGURE 1 Composited phylogeny indicating the relationships between taxa included in the study, based on cladograms published by previous authors (cited in the text). Taxa in red correspond to those included in the phylogenetic principal component analysis (PPCA) based on the measurements of the hindlimb long bones, taxa in green correspond to those included in the PPCA based on the lengths of the pedal phalanges, and taxa in blue are those included in both analyses

Additionally, the size effect on each axis of the morphospaces was calculated using phylogenetic generalized least squares (PGLS) regressions (Martins and Hansen, 1997), considering the geometric means as the independent variables. A PGLS regression allows the incorporation of the phylogenetic structure of samples as the error term of the regression equations, and then consideration of the biases caused by phylogeny in the calculation of the relationship between the analysed variables.

All these analyses were carried out using the software R 3.5.0 ( $R$ Development Core Team, 2018), and the PHYTOOLS (Revell, 2012), APE (Paradis et al. 2004) and PICANTE (Kembel et al. 2010) libraries.

Composited phylogenies were used for the phylogenetic PCA and the PGLS that synthetize the relationships between taxa included in the study (Fig. 1). These were based on previously published phylogenies of several theropod clades (Spicer and Dunipace, 2004; Livezey and Zusi, 2007; Hackett et al. 2008; Bunce et al. 2009; Wink et al. 2009; Makovicky et al. 2010; Xu et al. 2011; Carrano et al. 2012; Turner et al. 2012; Kimball et al. 2013; Wu et al. 2015; McFeeters et al. 2016; Apesteguía et al. 2016a; Lü et al. 2017; Tsogtbaatar et al. 2017; Xu and Qin, 2017; Xu et al. 2017, 2018; Gianechini et al. 2018; Hartman et al. 2019).

The morphological differences between unenlagiines and other dromaeosaurids were also evaluated through qualitative comparisons of the hindlimb bones, especially of the metatarsals and pedal phalanges. The morphology of dromaeosaurid taxa was observed directly from the holotypes of Deinonychus (YPM 5205), Bambiraptor (AMNH FR 30556) and Dromaeosaurus (AMNH FR 5356), and from the literature (e.g. Colbert and Russell, 1969; Ostrom, 1969, 1976; Norell and Makovicky, 1997, 1999; Burnham et al. 2000; Hwang et al. 2002; Xu, 2002; Burnham, 2004; Longrich and Currie, 2009; Turner et al. 2011, 2012; Pei et al. 2014; Lü and Brusatte, 2015; Xu and Qin, 2017). The observations concerning unenlagiines were made on the holotypes and referred materials of Buitreraptor (MPCA 245, MPCA 238, MPCA 478, and MPCN-PV-598), Neuquenraptor (MCF PVPH 77), Austroraptor (MML 195 and MML 220), and a cast of the holotype of Rahonavis (FMNH PR 2830). Additional comparisons with other theropod taxa were made using the literature (e.g. Russell and Dong, 1993; Karhu and Rautian, 1996; Mayr et al. 2007; Zhou et al. 2010; Zanno et al. 2011; McFeeters et al. 2016; and other references listed in Appendix S1) and, in the case of extant birds, also using the above-mentioned materials.

The curvature angles of unguals of unenlagiines and Laurasian dromaeosaurids were measured using the methodology applied by Fowler et al. (2009), which in turn is based on that of Pike and Maitland (2004). Both the external and inner curvature angles of the unguals are measured with this methodology, obtaining the angle between the base and the tip of the claw. However, as this methodology was used to measure ungual curvatures of extant taxa of birds with soft tissue on digits, some modifications were made. For extant birds, the base of the claw is considered at the point where the keratinous sheath emerges from the skin of the digit. However, in fossil unguals lacking the sheath and soft tissue, the same methodology cannot be applied for the measurement of the curvature angles. Accordingly, we take the proximodorsal tip of the ungual bone as the dorsal base to measure the external curvature angle, and the tip of the flexor tubercle as the ventral base (Fig. S1). However, the flexor tubercle shows two ventral tips in the unguals of the analysed theropods, separated by an extension of the side groove of the claw. In such cases, the distal tip was taken as the base to measure the angle of the inner curvature. The angles were taken from photographs of the ungual phalanges using the measure tool in Adobe Photoshop. The incomplete unguals which have not preserved the distal or the proximoventral ends were reconstructed, although in these cases it was indicated that the angle values are estimated.

\section{3 | RESULTS}

\section{1 | Description of the phylogenetic PCA based on measurements of the hindlimb long bones}

In the phylogenetic PCA analysis based on measurements of the long bones of the hindlimb (femur, tibia, and metatarsals), and including Mesozoic theropods (MzTer), extant birds and Dinornithiformes, the contributions of the osteological variables to the first phylogenetic principal component (PPC1) represent $57.2 \%$ and to the second phylogenetic principal component (PPC2) represent $30.1 \%$ of the total variation (Fig. 2). The PPC1 summarizes a major contribution of tibia and metatarsus lengths (negatively correlated with the PPC1) as well as that of the mediolateral width of metatarsus at midshaft (ML; positively correlated). The high negative PPC1 scores identify taxa with elongated and slender metatarsi and elongated tibiae, whereas the fewer negative and positive PPC1 scores set apart taxa with shorter and wider metatarsi and shorter tibiae. The PPC2 summarizes a major contribution of the femur length (positively correlated) and minor contributions from the metatarsus length and $M L$ (both variables negatively correlated). High positive PPC2 scores identify mainly taxa with elongated femora, and somewhat short and slightly slender metatarsi, whereas negative scores usually characterize taxa with shorter femora, and slightly longer and wider metatarsi (see also Appendix S2).

In general, extant birds and Dinornithiformes are partially segregated from the MzTer, toward negative scores of PPC1 and PPC2 (Fig. 2). This is mainly because these groups have longer and more slender metatarsi, longer tibiae, and shorter femora in comparison with the MzTer. 


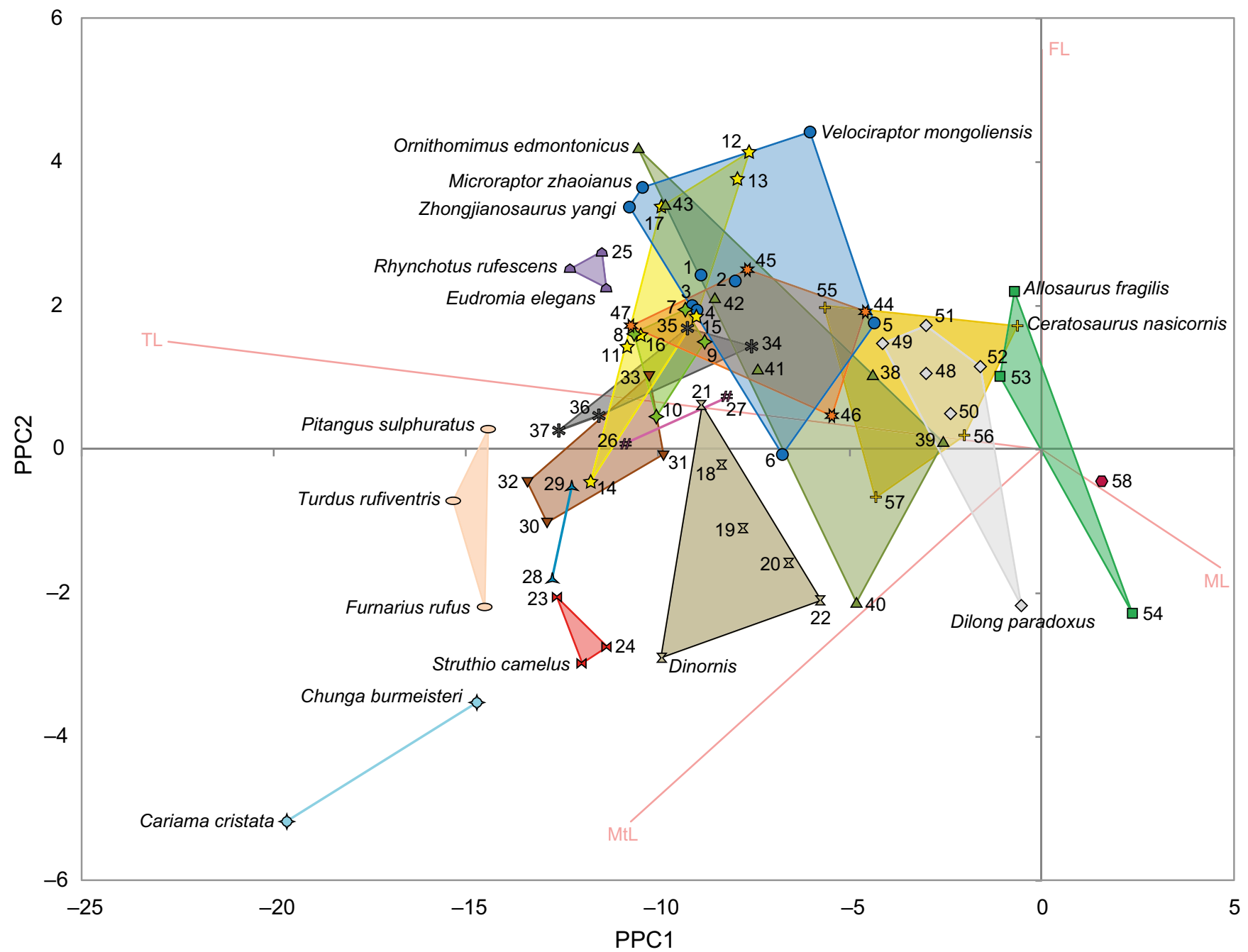

1- Buitreraptor gonzalezorum

2- Rahonavis ostromi

3- Mahakala omnogovae

4- Zhenyuanlong suni

5- Deinonychus antirrhopus

6- Bambiraptor feinbergi

7- Mei long

8- Sinornithoides youngi

9- Sinovenator changae

10- Anchiornis huxleyi

11- Archaeopteryx

12- Sapeornis chaoyangensis

13- Confuciusornis sanctus

14- Hongshanornis longicresta

15- Zhongjianornis yangi

16- Yanornis martini

17- Yixianornis grabaui

18- Anomalopteryx didiformis

19- Emeus

20- Euryapteryx

21- Megalapteryx didinus
22- Pachyornis

23- Pterocnemia pennata

24- Rhea americana

25- Nothoprocta cinerascens

26- Geranoaetus melanoleucus

27- Elanus leucurus

28- Polyborus plancus

29- Milvago chimango

30- Tyto alba

31- Bubo virginianus

32- Athene cunicularia

33- Asio flammeus

34- Haplocheirus sollers

35- Alnashetri cerropoliciensis

36- Linhenykus monodactylus

37- Parvicursor remotus

38- Garudimimus brevipes

39- Beishanlong grandis

40- Archaeornithomimus asiaticus

41- Gallimimus bullatus

42- Struthiomimus altus

43- Rativates evadens
44- Khaan mckennai
45- Wulatelong gobiensis
46- Chirostenotes pergracilis
47- Avimimus portentosus
48- Gorgosaurus libratus
49- Albertosaurus sarcophagus
50- Daspletosaurus torosus
51- Tarbosaurus bataar
52- Tyrannosaurus rex
53- Eustreptospondylus oxoniensis
54- Megalosaurus bucklandii
55- Coelophysis bauri
56- Dilophosaurus wetherilli
57- Elaphrosaurus bambergi
58- Herrerasaurus ischigualastensis

Herrerasauridae

\& non Tetanurae Neotheropoda

$\square$ basal Tetanurae

$\diamond$ Tyrannosauroidea

$\triangle$ Ornithomimosauria

is Oviraptorosauria

* Alvarezsauroidea

- Dromaeosauridae

$\diamond$ Troodontidae

今 Mesozoic Avialae

z Dinornithiformes

$\bowtie$ Struthioniformes

๑ Tinamiformes

\# Accipitridae

$\triangle$ Falconiformes

$\nabla$ Strigiformes

Passeriformes

$\&$ Cariamiformes

FIGURE 2 Morphospace obtained from the phylogenetic principal component analysis based on the measurements of the hindlimb long bones. PPC1, first phylogenetic principal component; PPC2, second phylogenetic principal component

The MzTer with high negative PPC1 scores include the alvarezsauroids, derived ornithomimids, some oviraptorosaurs, basal avialans, troodontids, microraptorines and unenlagiines.
All of them have elongated hindlimbs, with remarkably elongated and slender metatarsi and longer tibiae in comparison with the remaining MzTer. Moreover, many of these taxa are 
characterized by an arctometatarsalian or subarctometatarsalian condition.

Among unenlagiines, Buitreraptor clusters close to Mahakala, Zhongjianornis, Zhenyuanlong, Struthiomimus, Mei, Alnashetri and Sinovenator (Fig. 2). These taxa show a long metatarsus, although slightly shorter and wider than other MzTer such as the alvarezsaurids. Thus, they are located on fewer negative PPC1 scores and higher positive PPC2 scores. Rahonavis is closer to the oviraptorosaur Wulatelong than to Buitreraptor, presenting fewer negative PPC1 scores and slightly lower positive PPC2 scores. This separation appears because Rahonavis has a slightly shorter and wider metatarsus than Buitreraptor and the other taxa clustered with this Argentinian unenlagiine.

The eudromaeosaurs Deinonychus and Velociraptor segregate and locate on lower negative PPC1 scores than other dromaeosaurids, including Buitreraptor, since they have markedly shorter and wider metatarsi and shorter tibiae. In fact, Deinonychus lies closer to tyrannosaurids than to other dromaeosaurids. Velociraptor is located on remarkably higher positive PPC2 scores because it has an even shorter metatarsus and tibia, relative to the femur. Bambiraptor is markedly separated from other derived Laurasian dromaeosaurids, mainly because it has a comparatively long metatarsus.

\subsection{1 | Influence of phylogeny in the distribution of taxa across the morphospace}

The Blomberg $K$ values indicate that the taxa distribution along the PPC1 is strongly influenced by the phylogenetic relationships of major clades $(K=2.714$ ). PPC2 is less influenced by deep phylogenetic relationships, and is instead related to the influence of the phylogenetic structure of terminals and of more inclusive clades $(K=0.262$; Table $\mathrm{S} 1)$. Thus, the segregation and relatively scarcely overlapping distribution of the major clades along the PPC1 can be related to the high $K$ value of this axis. On the other hand, the low $\mathrm{K}$ value of PPC2 indicates that there are many convergences to extreme values in different terminal and less inclusive clades. The phylogenetic relationships plotted on the morphospace (i.e. phylomorphospace; Fig. 3) shows a main separation between derived or crown-group birds (including extant taxa and Dinornithiformes) and MzTer. Birds are grouping toward negative values of the PPC1, whereas MzTer are clustered at fewer negative and at positive values of PPC1. This separation occurs because birds have a generally longer and slender metatarsus and a longer tibia than MzTer. In addition, more derived taxa of some MzTer clades generally trend to locate at higher negative values of PPC1 (as can be observed in tyrannosauroids, ornithomimosaurs and alvarezsaurs). Meanwhile, the most primitive taxa considered in the study are grouped at the extreme positive values of PPC1, in accordance with their plesiomorphic metatarsal morphology (Fig. 3).

As was stated above, PPC2 summarizes morphological similarities between minor clades or terminals. Although PPC2 is less influenced by the phylogenetic relationships of major clades, the positive correlation of this component with the femoral length can partially explain the division between MzTer and derived avialans (extant birds and
Dinornithiformes). In the latter there is a general trend towards a significant shortening of the femur in comparison with MzTer, the reason why most of these are at negative values of the PPC2. The exception is the Tinamiformes, which are on positive values of PPC2, and thus significantly separated from the remaining modern birds.

The distribution of dromaeosaurids along the phylomorphospace (Fig. 3) shows that more basal taxa, such as Mahakala and the unenlagiines Buitreraptor and Rahonavis, are located on higher negative values of PPC1, whereas more derived taxa, i.e. Deinonychus, Velociraptor and Bambiraptor, are on lower negative values of PPC1. This distribution shows that the basal taxa have a longer metatarsus and tibia than the derived forms. Regarding the distribution of taxa along PPC2, dromaeosaurids do not show a clear trend. Basal taxa are located on similar values of PPC2, whereas microraptorines (at least those taxa considered in this analysis) are more widely distributed. Some microraptorines (i.e. Microraptor and Zhongjianosaurus) are on high positive values of PPC2, whereas others (i.e. Zhenyuanlong) are on similar PPC2 values to basal dromaeosaurids, with a shorter femur. Moreover, Microraptor and Zhongjianosaurus converge in the morphospace with derived ornithomimids with long femora. The derived dromaeosaurids are also widely distributed. Thus, Velociraptor is on high positive values of PPC2, close to some basal avialans; Bambiraptor is on negative values, close to taxa with a shorter femur and longer metatarsus; and Deinonychus is on an intermediate location near derived tyrannosaurids. The location of Velociraptor can be explained possibly by its comparatively long femur with respect to the other derived dromaeosaurids analysed here.

\subsection{2 | Influence of size in the distribution of taxa across the morphospace}

The PGLS regressions indicate that the PPC1 in the analysis based on dimensions of the long bones is significantly influenced by size $(F=7.318 ; P=0.009)$. The MzTer taxa with the largest body sizes are located towards the right side of the morphospace, on fewer negative and some positive values of the PPC1. Furthermore, the Dinornithiformes, which are the largest modern birds considered in the analysis, are located in the right part of the morphospace occupied by modern birds. These large-sized taxa are characterized by a comparatively short and wide metatarsus. On the other hand, smaller taxa with slender and longer hindlimbs are situated at the left of the morphospace, as in the case of certain MzTer or modern birds. Conversely, PPC2 ( $F=2.162 ; P=0.146)$ is not significantly influenced by size, thus agreeing with the distribution of taxa along the axis.

\section{2 | Description of the phylogenetic PCA based on lengths of the phalanges}

In the phylogenetic PCA made using the lengths of the phalanges, the contributions of the variables to PPC1 represent $39.0 \%$, and to PPC2, 29.1\% of the total variation (Fig. 4). Because these two axes 


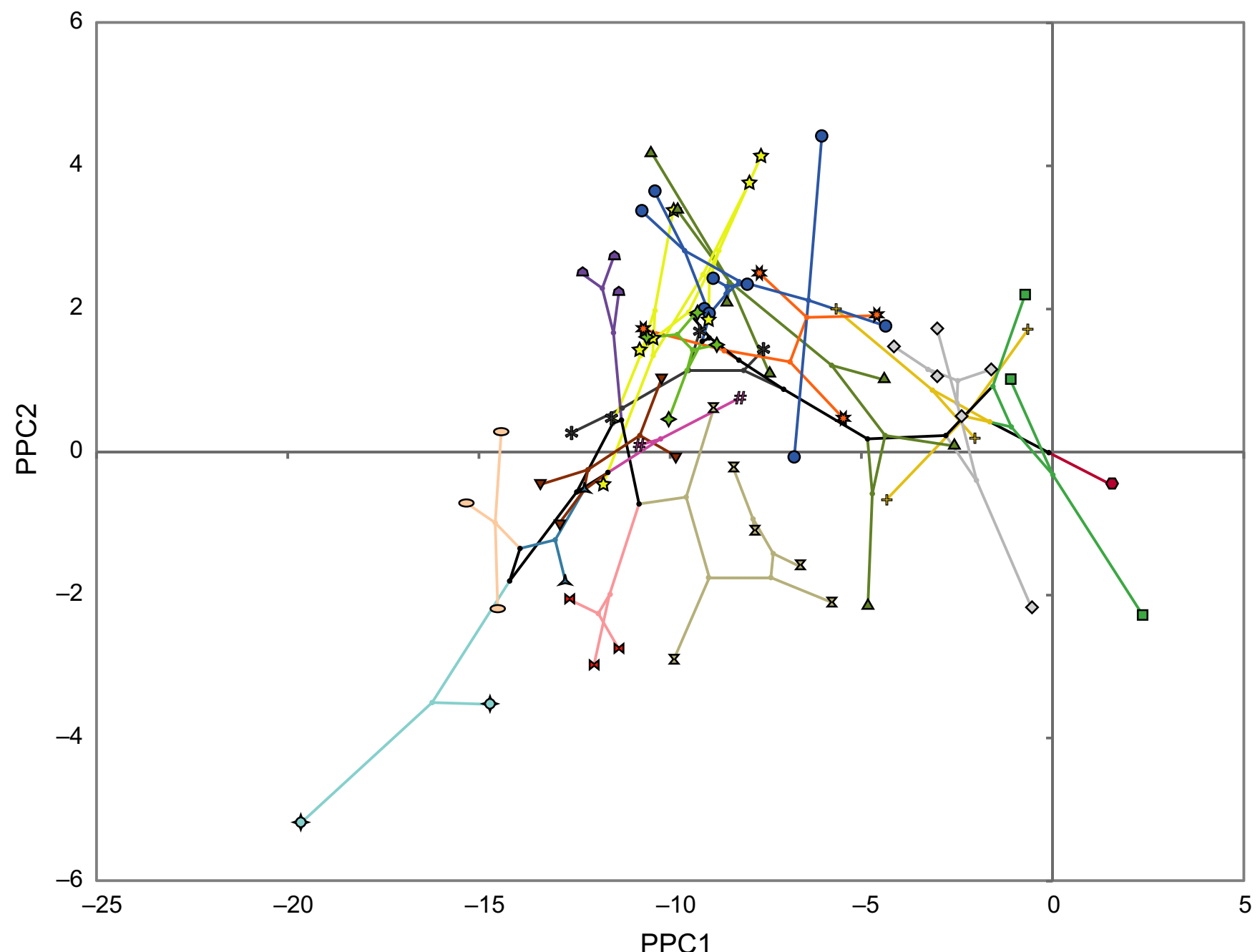

PPC1

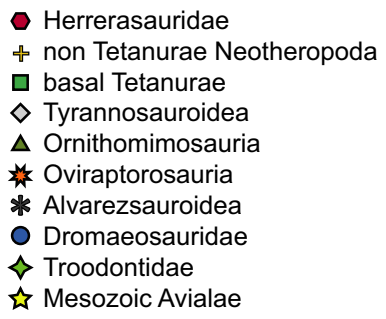

$\boldsymbol{z}$ Dinornithiformes

$\star$ Struthioniformes

๑ Tinamiformes

\# Accipitridae

$\Delta$ Falconiformes

$\nabla$ Strigiformes

O Passeriformes

$\&$ Cariamiformeas

FIGURE 3 Phylomorphospace obtained from the phylogenetic principal component analysis based on the measurements of the hindlimb long bones. PPC1, first phylogenetic principal component; PPC2, second phylogenetic principal component

explain a small percentage of the variation, we also analysed the third component (PPC3; $10.8 \%$ of the total variation).

In the graphic of PPC1 vs PPC2 (Fig. 4), PPC1 summarizes a major contribution of the lengths of the proximal phalanges, i.e. Ph. II-1, III-1, IV-1 and III-2 (positively correlated with this component), and the lengths of the distal pre-ungual phalanges, i.e. II-2, III-3 and IV-4 (negatively correlated with this component). In this way, high positive PPC1 scores depict taxa with elongated proximal phalanges, whereas high negative PPC1 scores characterize taxa with elongated distal phalanges. The PPC2 summarizes major contributions from the lengths of the proximal and middle phalanges of digit IV, i.e. IV-2 and IV-3 (positively correlated with this component), and the lengths of the proximal and distal pre-ungual phalanges of digits II and III (negatively correlated). Thus, high positive PPC2 scores indicate taxa with long phalanges IV-2 and IV-3, whereas high negative PPC2 scores depict taxa with long proximal or distal pre-ungual phalanges on the other two main digits (II and III). In sum, taxa with high positive PPC1 and high negative PPC2 scores have more elongated proximal phalanges, whereas those taxa located on negative PPC1 scores have relatively more elongated distal phalanges.

In the graphic of PPC2 vs PPC3 (Fig. 5) the PPC3 (10.8\% of the total variation) summarizes major contributions from the lengths of all the phalanges of digit II (positively correlated with this component). This component also summarizes contributions of the lengths 


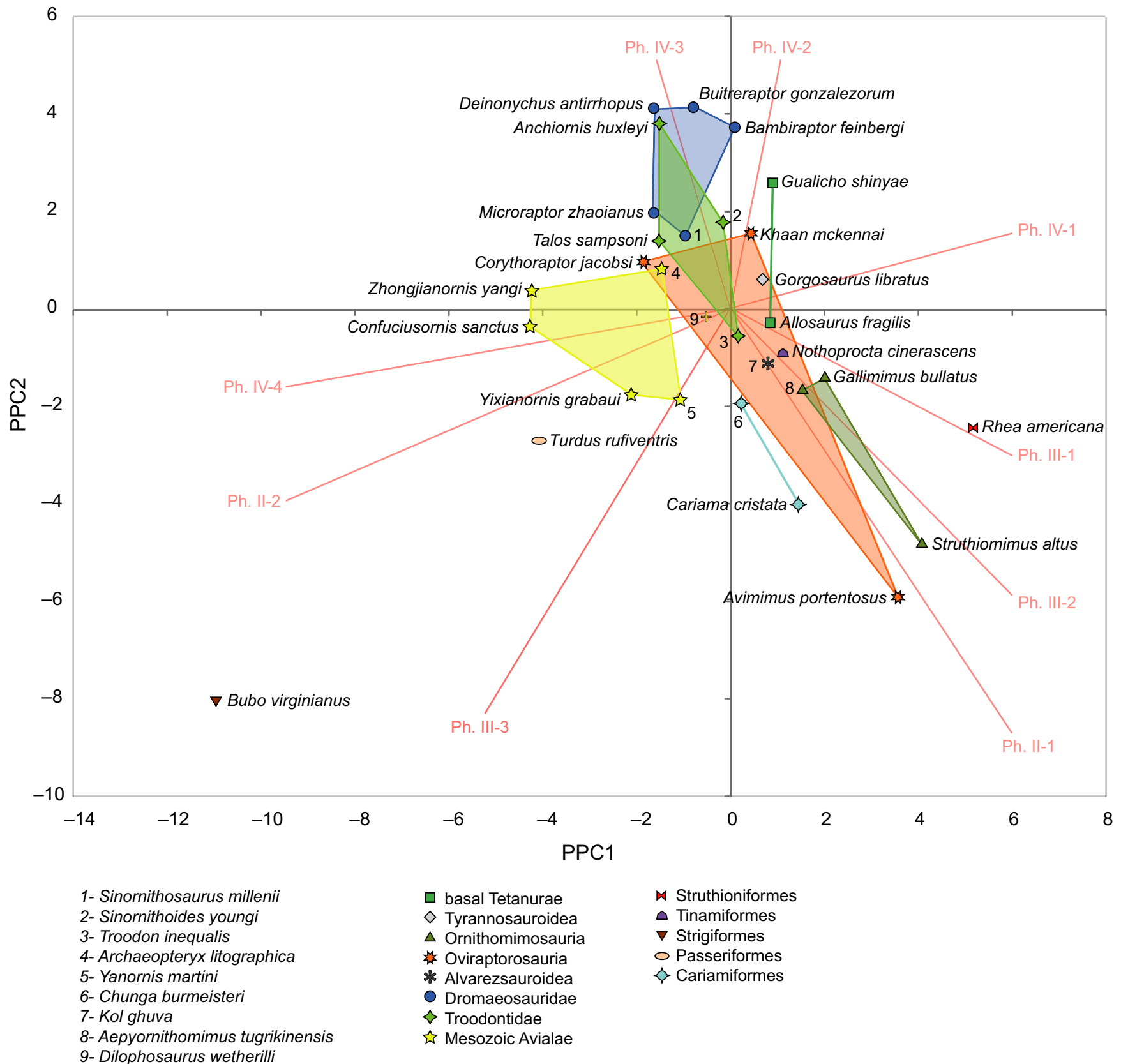

FIGURE 4 Morphospace obtained from the phylogenetic principal component analysis based on the lengths of the pedal phalanges [first phylogenetic principal component (PPC1) vs. second phylogenetic principal component (PPC2)]

of the phalanges of digit III, mainly Ph. III-2 and III-3 (negatively correlated). Thus, high positive PPC3 scores depict taxa with a long digit II, whereas high negative PPC2 scores depict taxa with long phalanges III-2 and III-3 (see also Appendix S2).

Non-coelurosaurian theropods are widely dispersed across the morphospace (Figs 4 and 5). Regarding coelurosaurs, the position of the tyrannosaurid Gorgosaurus is mainly influenced by relatively long proximal phalanges and especially by the phalanges of digit IV. Oviraptorosaurs show a widespread distribution over the morphospace (Figs 4 and 5). Ornithomimosaurs are on positive PPC1 and PPC3 scores and on negative PPC2 scores due to their relatively elongated proximal phalanges and digit II.
Troodontids show a distribution in the morphospace that is mainly similar to that of the dromaeosaurids (Figs 4 and 5). Troodon is an exception because it has negative PPC2 scores, having a shorter digit IV than the other analysed troodontids.

In the morphospace, dromaeosaurids cluster at values close to zero of PPC1, high positive of values of PPC2, and high negative PPC3 scores (Figs 4 and 5). Most members of the clade are on negative PPC1 scores, except Bambiraptor which is on a low positive PPC1 value. Deinonychus, Buitreraptor and Bambiraptor share higher positive PPC2 scores whereas Microraptor and Sinornithosaurus have lower positive scores for this component. The high positive values of PPC2 of dromaeosaurids are linked to a remarkably elongated digit 


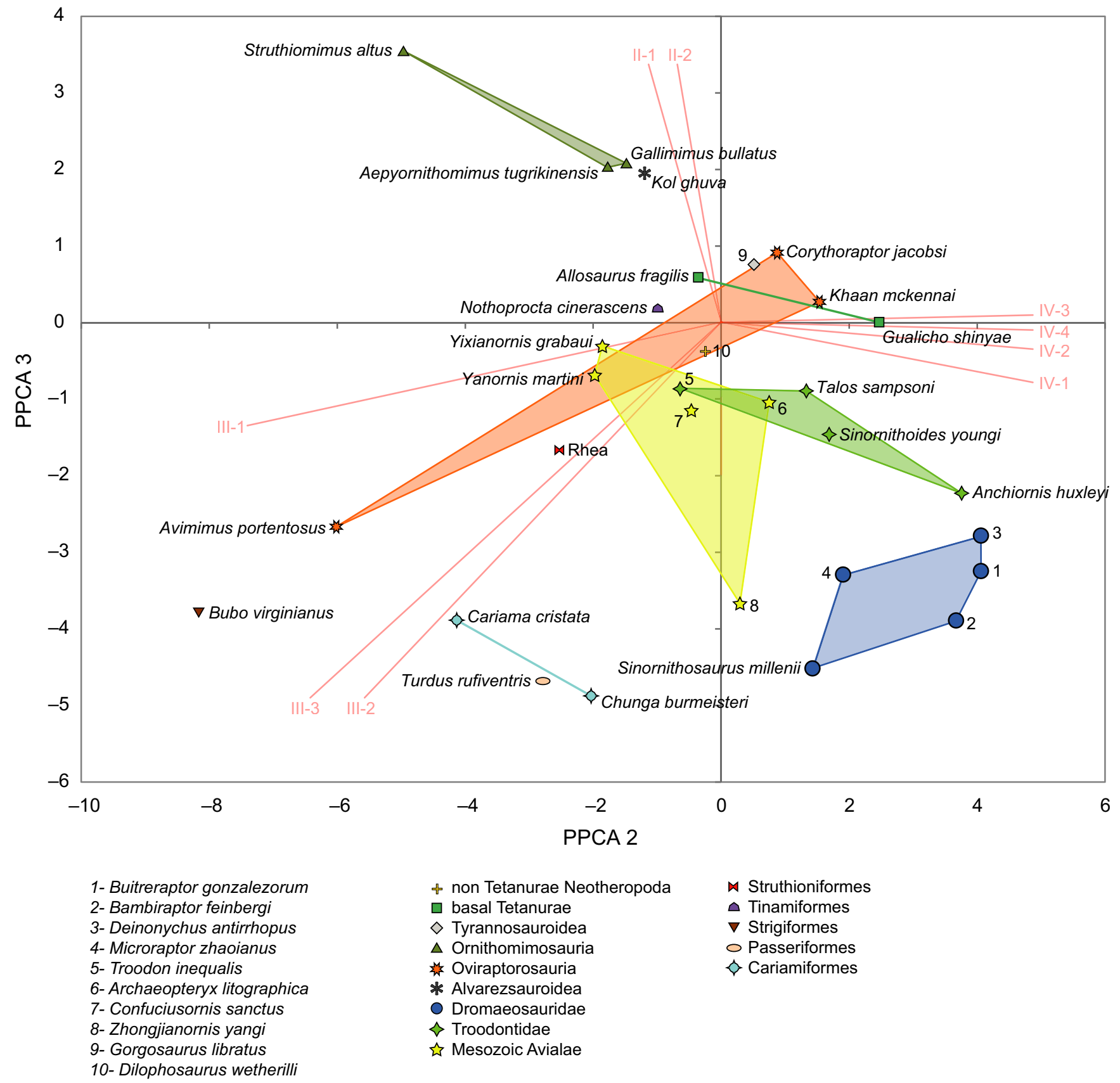

FIGURE 5 Morphospace obtained from the phylogenetic principal component analysis based on the lengths of the pedal phalanges phalanges [second phylogenetic principal component (PPC2) vs. third phylogenetic principal component (PPC3)]

IV, which is a feature mainly due to the elongation of the phalanges IV-2 and IV-3. The high negative values on PPC3 are also mainly related to the length of the phalanges of digit IV, but also influenced by the length of Ph. III-2 and III-3. Deinonychus and Buitreraptor show a relatively long digit IV in comparison with other dromaeosaurids. The position of Deinonychus at higher negative PPC1 scores is specifically influenced by the length of phalanx IV-4. Sinornithosaurus is located at high PPC3 values due to the elongated phalanges III-3 and II-2. The position of Microraptor is due to a shorter digit IV in comparison with Deinonychus, Buitreraptor and Bambiraptor. On the other hand, its higher negative PPC1 score is influenced by the length of phalanx IV-4.
Mesozoic avialans are on negative PPC1 and PPC 3 scores and positive and negative PPC2 scores (Figs 4 and 5). These locations on the morphospace are mainly attributable to these taxa having a long digit IV and elongated distal phalanges of the digits II, III, and IV.

Extant birds are mainly distributed along negative PPC2 and PPC3 scores (Figs 4 and 5); however, a dichotomy can be observed along the PPC1 because some taxa are on positive scores, a position mainly influenced by the long proximal phalanges of the digits II, III, and IV, and others on negative ones, a position markedly influenced by the length of the distal phalanges of the digits II, III and IV. 


\subsubsection{Influence of phylogeny in the distribution of taxa across the morphospace}

The Blomberg $K$ values indicate that the taxon distribution along the PPC1, PPC2 and PPC3 axes is strongly influenced by the relationships between terminals. The distribution is also affected by less inclusive clades in the case of PPC1 $(K=0.303)$ and PPC2 $(K=0.376)$. Additionally, the dispersion of taxa is linked to the large number of morphological convergences between distantly located taxa (Table S2). The PPC3 shows a $K$ value closer to $1(K=0.811)$, and thus it fits more closely with a stochastic model (i.e. the distribution of taxa follows their phylogenetic relationships, but is not particularly strongly influenced either by deep nodes or by terminal relationships).

For instance, basal taxa included in the analysis, such as basal tetanurans and the basal coelurosaur Gorgosaurus, are almost overlapping on similar values of PPC1, although they are separated along PPC2 and PPC3 (Figs 6 and 7).

Dromaeosaurids show a certain amount of convergence between basal and derived taxa, since Buitreraptor is located near the derived dromaeosaurids Deinonychus and Bambiraptor (Figs 6 and 7). These three taxa have a comparatively elongated digit IV relative to Microraptor and Sinornithosaurus, which are more derived than Buitreraptor, although more basal with respect to Deinonychus and Bambiraptor (Fig. 1).

\subsubsection{Influence of size in the distribution of taxa across the morphospace}

The results of the PGLS regressions indicate that the axes that compose the morphospace analysed for the phalanx measurements (i.e. PPC1, PPC2, and PPC3) are not significantly influenced by body size (PPC1: $F=1.253, P=0.2722 ;$ PPC2: $F=2.513, P=0.1238$; $P$ PC3: $F=0.6881, P=0.6881)$. Accordingly, the distribution of taxa along the axes does not follow a pattern controlled by size.

\section{4 | DISCUSSION}

Previous authors have enumerated the distinctive morphological features of animals traditionally considered as 'cursorials': relatively long limbs; hinge-like joints; distal limb segments proportionally elongated; reduction, compression or loss of the ulna and fibula, and of the lateral metapodials and phalanges; reduction or loss of distal muscular groups or proximal location of their scars; a limb motion restricted to the sagittal plane; acquisition of digitigrade or unguligrade stance; and metapodials interlocked, fused or reduced to a single element (Gambaryan, 1974; Coombs, 1978; Hildebrand, 1982, 1985, 1988; Garland and Janis, 1993; Carrano, 1999). From the perspective of locomotor performance, animals known as cursorials have the capacity to move at greater velocities or for long distances with a low energetic cost (Gregory, 1912; Garland and Janis, 1993; Stein and Casinos, 1997; Carrano, 1999). However, Carrano (1999) considered that a discrete categorization of the locomotor habits might not be appropriate. Instead, these habits should be evaluated along a multivariate continuum between two locomotor extremes, i.e. strictly graviportal and cursorial. Theropods can be generally considered as cursorial animals (or 'subcursorial', according to Coombs, 1978), as they were bipeds, digitigrades and with long and parasagittally oriented hindlimbs (Farlow et al. 2000). However, different theropod taxa would be dispersed along a continuum that includes different grades of cursoriality. The distribution in the morphospace obtained in the multivariate analyses performed could indeed reflect such ecomorphological diversity. Taxa with more elongated distal segments of the hindlimbs (i.e. tibia and metatarsus), a more slender and compressed metapodium, and reduced lateral pedal digits likely had a greater cursorial capacity (Hildebrand, 1988; Carrano, 1999). These taxa would locate closer to the 'cursorial extreme' of the multivariate continuum than taxa with shorter segments of the hindlimb, with a more robust metapodium, and lateral digits less reduced.

The elongation of the distal elements of the hindlimb (tibia and metatarsus) allows increasing of the stride length and speed of movements, which are related to a greater cursorial capacity (Carrano, 1999; Fowler et al. 2011). Garland and Janis (1993) explained that the ratio between the lengths of metatarsus and femur (MT/F) was repeatedly considered by some authors as a predictor of locomotor performance in fossil forms. However, Garland and Janis (1993) and other authors (Gatesy and Middleton, 1997; Zeffer et al. 2003; Habib and Ruff, 2008) warned that ratios between hindlimb bones are not good predictors of the type of locomotion, so limb proportions must be considered with caution. Thus, it is important to also take into account qualitative aspects, such as the morphology of the metapodium, to make inferences about locomotor abilities of specific taxa.

The arctometatarsalian and subarctometatarsalian conditions could confer significant cursorial capabilities to their bearers. Some authors (Holtz, 1994; White, 2009) have noted that theropod taxa presenting these conditions have distal elements of the hindlimb significantly more elongated than taxa with a plesiomorphic metapodium. Moreover, many authors have postulated biomechanic hypotheses about the performance of the arctometatarsalian and subarctometatarsalian foot (Coombs, 1978; Wilson and Currie, 1985; Holtz, 1994; Snively and Russell, 2002, 2003; Snively et al. 2004; White, 2009). These authors indicated how the interaction between metatarsals and the transference of forces along the metatarsus provide advantages during locomotion, and how this could represent benefits for the cursorial habit.

In extant terrestrial birds with a cursorial locomotor mode and walking capacity (e.g. ratites such as ostriches, emus, Pterocnemia and Rhea), the pre-ungual phalanges tend to shorten distally (Fisher, 1946; Hopson, 2001; Kambic, 2008; Fowler et al. 2011). Furthermore, in these birds the foot is symmetrical, with the digit III, as the main weight bearer, being more developed, and with non-ginglymoid interphalangeal articular surfaces. In contrast, digits II and IV have a length similar to each other, being shorter than digit III, and have more ginglymoid interphalangeal articular facets, indicating that they were under 


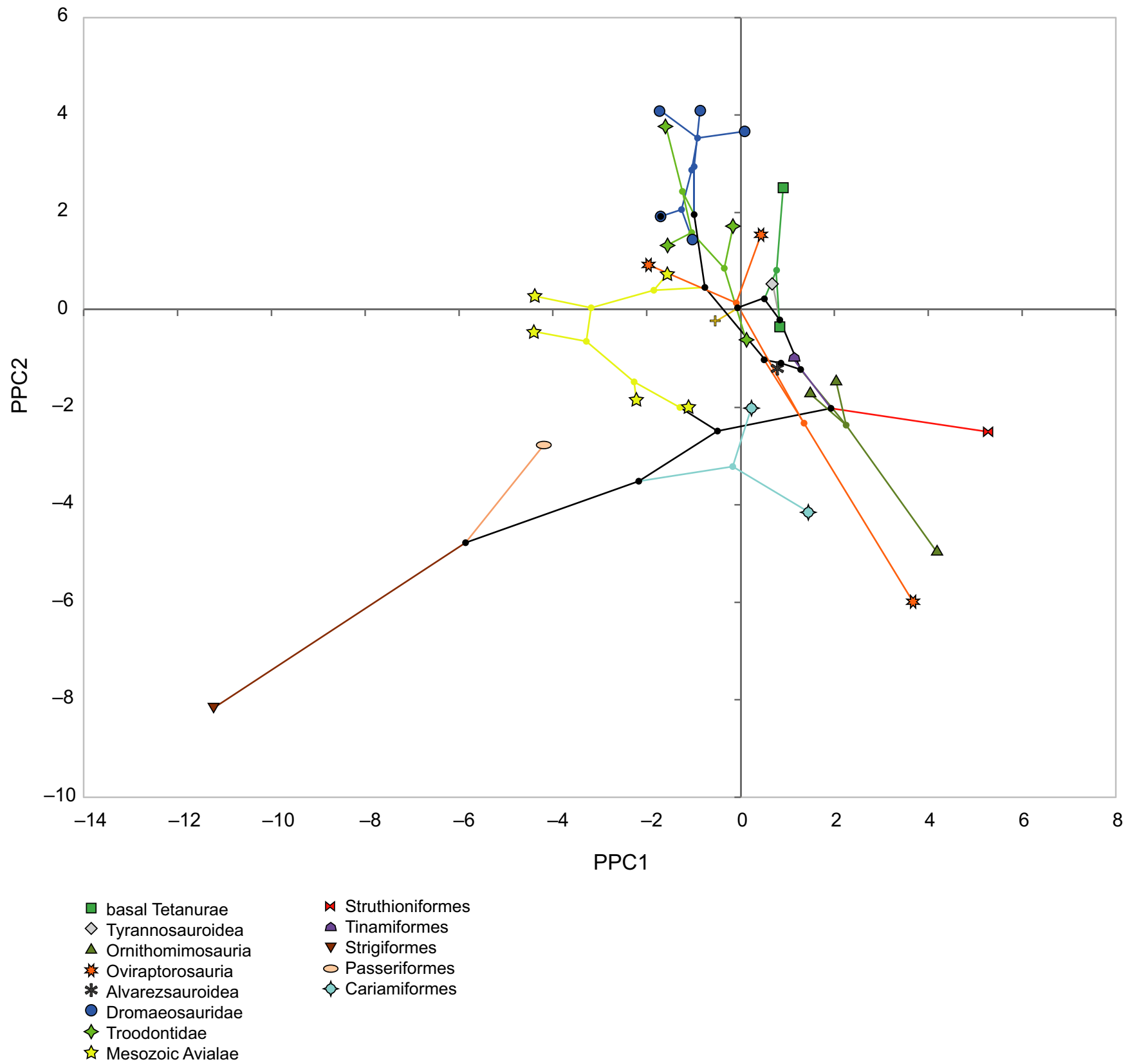

FIGURE 6 Phylomorphospace obtained from the phylogenetic principal component analysis based on the lengths of the pedal phalanges [first phylogenetic principal component (PPC1) vs. second phylogenetic principal component (PPC2)]

higher torsional efforts (Abourachid and Renous, 2000; Moreno et al. 2007; Fowler et al. 2011). Similar features are observed especially in MzTer taxa which are considered to have had greater cursorial capabilities, much of them possessing long tibiae and metatarsi, and an arctometatarsalian condition, such as ornithomimids, alvarezsaurids, caenagnathids and Avimimus (e.g. Osmólska et al. 1972; Russell, 1972; Coombs, 1978; Kurzanov, 1981; Osmólska, 1981; Karhu and Rautian, 1996; Paul, 1998; Vickers-Rich et al. 2002; Makovicky et al. 2004; Fowler et al. 2011; Xu et al. 2011; Currie et al. 2016; Funston et al. 2016; McFeeters et al. 2016; Tsogtbaatar et al. 2017).

By contrast, extant birds with a grasping foot are characterized by an elongation of the distal pre-ungual phalanges of the digits, especially the penultimate phalanx (Fisher, 1946; Hopson, 2001; Zhou and Farlow, 2001; Kambic, 2008; Fowler et al. 2011; Kavanagh et al. 2013). This feature can be observed both in perching and in raptorial extant birds. The elongation of the distal phalanges is convergently observed even in arboreal mammals which have grasping autopodia, such as the sloths (Kavanagh et al. 2013, and references therein).

\section{1 | Interpretation of the phylogenetic PCAs: their significance for the locomotor habits of theropods}

Taking into account the diverse factors and how they affect the hindlimb elements differentially, it is important to consider both analyses together (i.e. proportions of the long bones and the phalanges) 


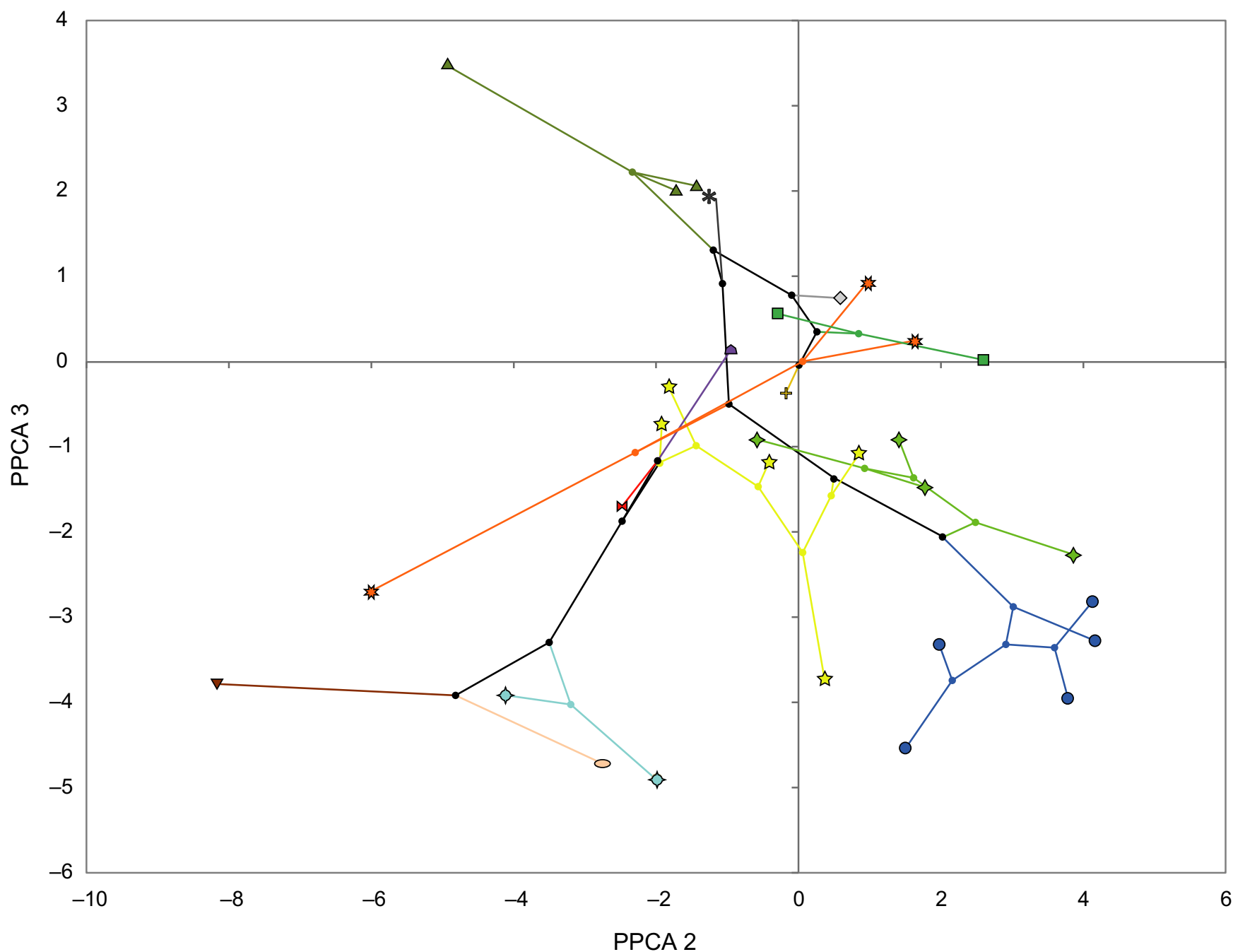
$\bowtie$ Struthioniformes
๑ Tinamiformes
$\nabla$ Strigiformes
○ Passeriformes
$\Leftrightarrow$ Cariamiformes

in Oviraptorosauria

* Alvarezsauroidea

- Dromaeosauridae

$\diamond$ Troodontidae

s Mesozoic Avialae

PPCA 2

FIGURE 7 Phylomorphospace obtained from the phylogenetic principal component analysis based on the lengths of the pedal phalanges ([second phylogenetic principal component (PPC2) vs. third phylogenetic principal component (PPC3)]

to make adequate inferences about the locomotor habits of theropods. For instance, Avimimus and Sinornithoides are very close to each other in the phylogenetic PCA morphospace constructed from the long bone measurements, and there are no evident differences between the two taxa (Fig. 2). However, the second phylogenetic PCA based on the lengths of the phalanges reveals clear dissimilarities between these taxa (Figs 4 and 5). The latter analysis indicates that the cursorial capacities of Avimimus are greater than those of Sinornithoides, whose phalangeal proportions are possibly more related to a grasping function.

Based on the results of the second phylogenetic PCA made using lengths of the phalanges, taxa such as Avimimus, Cariama and Rhea are considered to have greater cursorial abilities (Gonzaga,
1996; Picasso, 2010; Degrange, 2017). These taxa have elongated proximal phalanges and a long digit III (Figs 4, 5 and 8). Other taxa, such as ornithomimids (especially Struthiomimus), also have traits related to more cursorial capabilities, i.e. more elongated proximal phalanges, although their digit III is not as long as in the above-mentioned taxa. Taxa such as Gualicho, Allosaurus, Gorgosaurus, Corythoraptor and Khaan have slightly more elongated proximal phalanges, so these could have had certain cursorial capacities, also supported by taking into account that they have a digit IV almost as long as digit III. Instead, Bubo, Turdus, as well as some Mesozoic avialans clustered close to these, have a foot with elongated distal phalanges, possibly pointing to more advanced grasping capacities. 
(a)

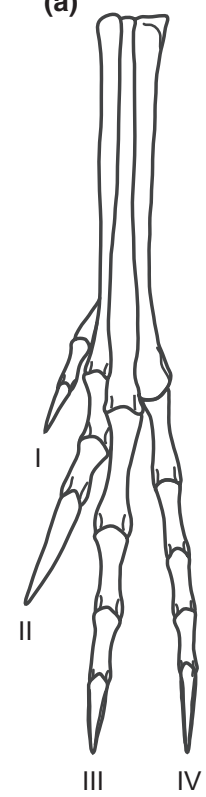

(b)

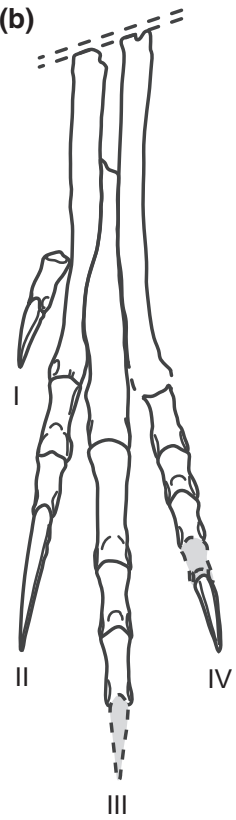

(c)

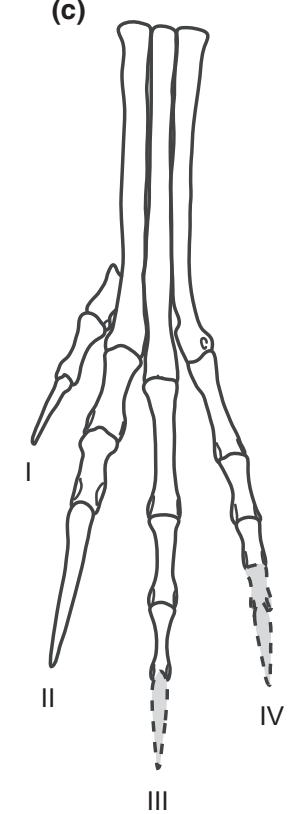

SOCIETY
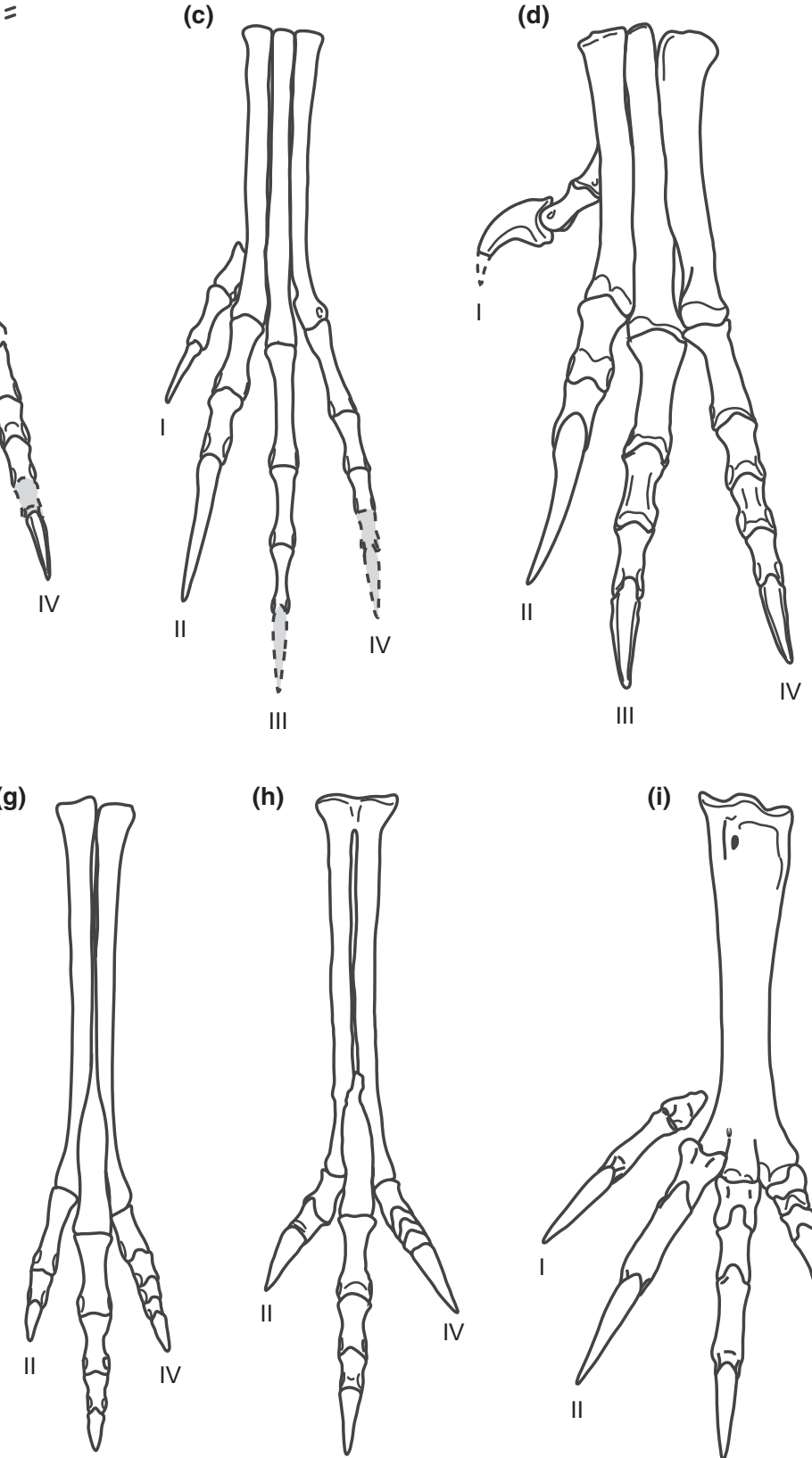

III (h)

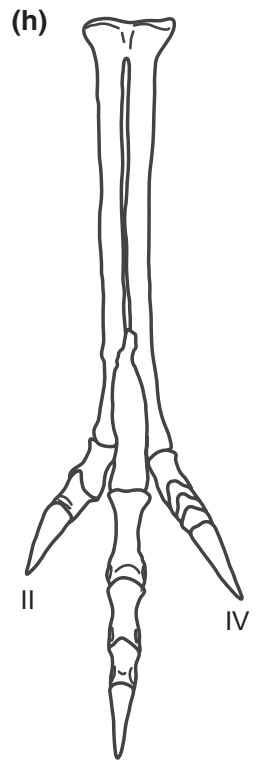

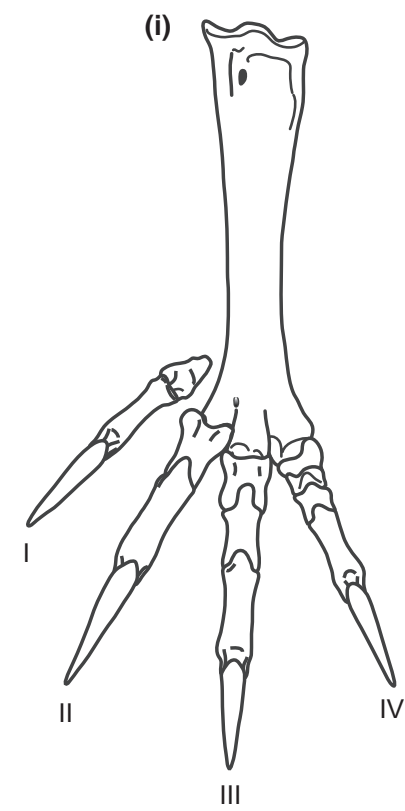

(e)

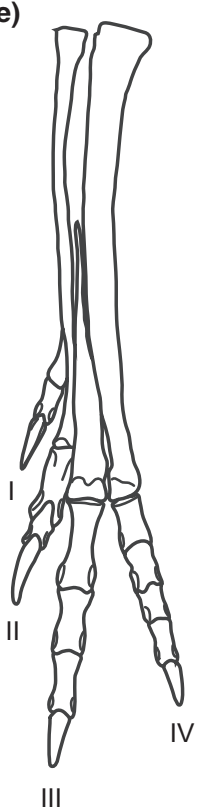

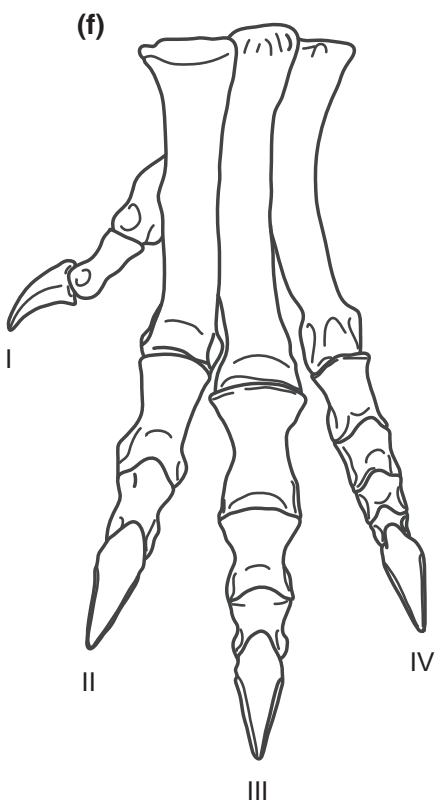

(g)

FIGURE 8 Comparisons between the autopodium of several theropod taxa, including unenlagiines and some extant birds, in anterior view. (a) Buitreraptor gonzalezorum (based on MPCN-PV-598). (b) Neuquenraptor argentinus (based on the holotype, MCF-PVPH-77; phalanges III-4 and IV-4 are missing in the original material). (c) Rahonavis ostromi (based on a cast of the holotype, FMNH PR 2830; phalanges III-4, IV-4 and IV-5 are missing in the original material). (d) Deinonychus antirrhopus. (e) Talos sampsoni. (f) Allosaurus gracilis. (g) Gallimimus bullatus. (h) Avimimus portentosus. (i) Bubo virginianus (based on MACN 2056a). (j) Cariama cristata (based on MACN 23873). (a) is inverted from the original material to compare better to the remaining taxa. In (i) and (j) the first digit is showed disarticulated from its natural position (totally turned backwards) for better visualization. (d), (f) and (g) modified from Fowler et al. (2011); (e) based on Zanno et al. (2011); (h) based on Vickers-Rich et al. (2002)

The position of dromaeosaurids, including Buitreraptor, as well as that of other taxa, such as Anchiornis, in the morphospace is related to their long digit IV and elongated distal phalanges (Figs 4, 5 and 8). This feature could be related to their particular pedal morphology in which digit II is markedly shortened and thus digits III and IV are the main structures of the foot support (Ostrom, 1969; Zhen et al. 1994; Lockley et al. 2004; Kim et al.
2008; Li et al. 2008; Senter, 2009; Xing et al. 2009; Mudroch et al. 2011).

In the phylogenetic PCA based on measurements of the long bones (Fig. 2) the PPC2 is less influenced by phylogeny and thus the distribution of taxa along this axis could support a clearer habit-related separation. The MzTer with higher positive values of PPC2 (Allosaurus, Ceratosaurus, Beishanlong, Garudimimus) have short and 
robust metatarsi. These taxa can be considered to have less advanced cursorial abilities than those taxa located at low positive to negative values of PPC2 (Dilong, Archaeornithomimus, Elaphrosaurus and Herrerasaurus), taxa which have longer and slender metatarsi. Modern birds also show the same general trend.

Along the PPC1, taxa having positive to low negative scores can be considered as having less cursorial capacities than those located at higher negative scores (Fig. 9). Accordingly, taxa such as Linhenykus and Parvicursor are interpreted as highly cursorial, an interpretation that is consistent with their highly derived, markedly elongated and slender arctometatarsus (Karhu and Rautian, 1996; Xu et al. 2011, 2013). Unfortunately, these two taxa have not preserved all the pedal phalanges and so they cannot be included in the second analysis based on the lengths of the phalanges.

Our quantitative analyses, in addition to other features already described (i.e. subarctometatarsal configuration; Gianechini et al. 2018; Novas et al. 2018), indicate that Buitreraptor could have had high cursorial capabilities. Other MzTer with similar locomotor capacities are the dromaeosaurid Zhenyuanlong and the troodontids Sinovenator and Mei, which all have an arctometatarsalian or subarctometatarsalian condition (Xu et al. 2002; Xu and Norell, 2004; Makovicky et al. 2005; Gao et al. 2012; Lü and Brusatte, 2015; Gianechini et al. 2018; Novas et al. 2018). Furthermore, these taxa present proportions of the hindlimb and pes that are similar to those of non-dromeosaurid theropods such as Struthiomimus, a probably markedly cursorial ornithomimid, as also indicated by the phylogenetic PCA based on the lengths of the phalanges. Notwithstanding, Buitreraptor has proportions of the phalanges indicating grasping adaptations and related to a lower cursorial performance. Unfortunately, measurements of the phalangeal lengths for Sinovenator, Mei and Zhenyuanlong were difficult to obtain because of the fragmentary preservation of the specimens, as well as the incomplete information offered by the descriptions of these taxa. However, in Sinovenator the phalanges of digit III appear to shorten distally and phalanx IV-4 is slightly longer than IV-3 (Xu, 2002).

\section{2 | Functional implications of the dromaeosaurid hindlimb morphology, and differences between unenlagiines and eudromaeosaurs}

\subsection{1 | Functional implications related with the proportions of the long bones}

The main differences between the hindlimbs of unenlagiines and eudromaeosaurs are related to the relative length and form of the metatarsus, as well as to the morphology of the phalanges of digit II (Gianechini and Apesteguía, 2011; Porfiri et al. 2011; Agnolín and Novas, 2013; Gianechini et al. 2018). The results of the phylogenetic PCAs indicate that in unenlagiines (except in Rahonavis), the metatarsus is significantly elongated when compared with the femur and tibia. Additionally, the lateromedial width of the metatarsus (ML) is significantly reduced related to its total length (MtL; except in Rahonavis) (Figs 8 and 9). By contrast, in eudromaeosaurs, the metatarsus is definitely shorter, and the $\mathrm{ML} / \mathrm{MtL}$ ratio is higher. These comparisons indicate that the metatarsus of eudromaeosaurs is more robust overall than that of the unenlagiines. Bambiraptor is not a eudromaeosaur, although it has morphological characters of the autopodium more similar to those of eudromaeosaurs and also it is phylogenetically closer to these than to other dromaeosaurids (Fig. 1).

The metatarsi of Neuquenraptor (MCF PVPH 77) and Austroraptor (MML 195) are incomplete, although their approximate length can be estimated, indicating that they were very elongated with respect to the tibia and femur. Thus, these taxa possibly had length proportions of the hindlimb bones much similar to those of Buitreraptor.

The proportions of the hindlimb long bones of Buitreraptor are remarkably different with respect to those of Bambiraptor and the eudromaeosaurs analysed here, i.e. Velociraptor and Deinonychus (Fig. 9). Instead, Buitreraptor is more similar in this respect to other taxa with a relatively elongated metatarsus, such as Mahakala, Alnashetri, Zhongjianornis, Zhenyuanlong, Sinovenator and Mei. These taxa are similar in size or smaller than Buitreraptor (Xu et al. 2002; Xu and Norell, 2004; Turner et al. 2007, 2011; Zhou et al. 2010; Gao et al. 2012; Makovicky et al. 2012, 2016; Lü and Brusatte, 2015). According to previous authors, similar size and hindlimb proportions would presumably indicate a similar locomotor mode (Holtz, 1994; Gatesy and Middleton, 1997; White, 2009).

Rahonavis departs from the general morphology of other unenlagiines by its shorter tibia, as well as shorter and wider metatarsus (Forster et al. 1998; Figs 8 and 9). Nevertheless, Rahonavis has hindlimb proportions more similar to those of unenlagiines than those of eudromaeosaurs, especially because it has a comparatively short femur and long tibia. Thus, Rahonavis can be considered as the least cursorial unenlagiine analysed, although clearly more cursorial than the eudromaeosaurs.

\subsection{2 | Functional implications inferred from proportions of the pedal phalanges}

The only unenlagiine to date with all the pedal phalanges preserved is Buitreraptor. Our results indicate that it has proportions of the phalanges similar to those of Bambiraptor and of the eudromaeosaur Deinonychus. The three taxa share their markedly elongated digit IV, which has a total length greater than that of digit III (Fig. 8). We can estimate that Neuquenraptor and Rahonavis have a digit IV shorter than the digit III, as do Sinornithosaurus and Microraptor, because the sum of lengths of the other pre-ungual phalanges of digit IV is significantly lower than the total length of digit III. Thus, the complete digit IV would have been slightly shorter than digit III, even if Ph. IV-4 had the same length or was even slightly longer than Ph. IV-3. By contrast, in other MzTer included in the analysis such as derived troodontids, non-paravian coelurosaurs, and basal tetanurans, the digit III is clearly the longest and digit IV is significantly shorter. These inter-digit proportions are linked with the cursorial abilities of the 


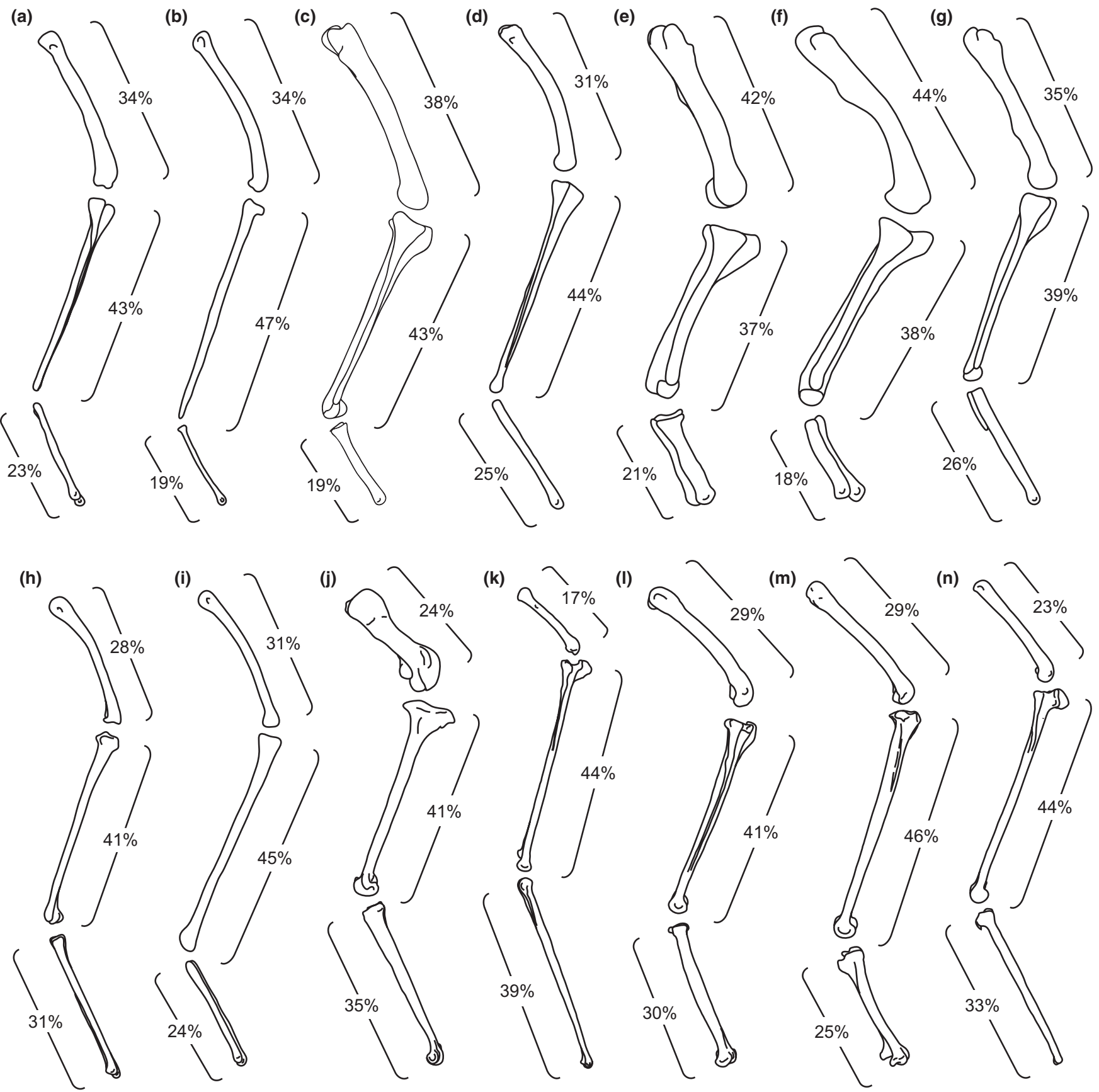

FIGURE 9 Comparisons of the hindlimb bones of different theropod taxa, including unenlagiines and extant birds, documenting the proportional lengths of the femur, tibia and metatarsus. (a) Buitreraptor gonzalezorum (based on MPCN-PV-598). (b) Rahonavis ostromi (based on a cast of the holotype: FMNH PR 2830). (c) Deinonychus antirrhopus. (d) Sinornithoides youngi. (e) Tyrannosaurus rex. (f) Allosaurus fragilis. (g) Struthiomimus altus. (h) Parvicursor remotus. (i) Archaeopteryx litographica. (j) Struthio camelus (based on CFA-OR-1560). (k) Cariama cristata (based on MACN 23873). (I) Geranoaetus melanoleucus (based on MACN 2129). (m) Bubo virginianus (based on MACN 2056a). (n) Furnarius rufus (based on MACN 68647). Hindlimbs are not to scale. (c), (e) and (g) modified from Ostrom (1976); (d) based on Russell and Dong (1993); (f) modified from Gatesy and Middleton (1997); (h) based on Karhu and Rautian (1996); (i) based on Mayr et al. (2007)

taxa involved (Abourachid and Renous, 2000; Moreno et al. 2007; Fowler et al. 2011). Accordingly, the length proportions of dromaeosaurids digits, including unenlagiines and especially Buitreraptor, seem to indicate a restriction to their cursorial habit.

Furthermore, dromaeosaurids show a significant elongation of the distal pre-ungual phalanges, a feature related to grasping capacities (see literature cited above). In extant birds with a grasping foot, such as Turdus and Bubo, the distal phalanges are significantly elongated (Appendix S1 and Fig. 8), independently of their ecological habits and the type of objects they usually hold with their feet. Generally, in unenlagiines, the length proportions of the distal phalanges of digit III are similar to those of the eudromaeosaur Deinonychus. However, in unenlagiines the second phalanx of digit II is shorter than the first one (Appendix S1), indicating 
slightly lower grasping capacities. In other dromaeosaurids, such as Microraptor, Ph. III-3 is significantly shorter than III-2, a feature that also could indicate poorer grasping capacities. Unfortunately, the lack of preserved elements prevents a more accurate analysis of the phalangeal proportions of Neuquenraptor and Rahonavis. However, the available data and the apparently long distal phalanges of digit IV in Neuquenraptor indicate that it probably had more accentuated grasping capacities than other unenlagiines, resembling those of Bambiraptor and the eudromaeosaur Deinonychus (Appendix S1).

\subsection{3 | Functional implications related to qualitative aspects of the metatarsus and motion range of digits}

Regarding its qualitative features, the subarctometatarsalian condition of unenlagiines also supports the presence of high cursorial abilities within the group. This condition is observed in Buitreraptor, Neuquenraptor, and possibly Austroraptor (based on the specimen MML 220). However, Rahonavis has a non-subarctometatarsalian metatarsus, indicating less cursorial abilities than other unenlagiines. Such a condition is also observed in Bambiraptor and eudromaeosaurs, which have a metatarsus more similar to the plesiomorphic condition (Ostrom, 1969; Barsbold, 1983; Norell and Makovicky, 1997; Turner et al. 2012; Brusatte et al. 2013).

Additionally, previous authors noted differences in the distal articular surfaces of metatarsals between unenlagiines and eudromaeosaurs (e.g. Agnolín and Novas, 2011; Fowler et al. 2011; Gianechini et al. 2018). In eudromaeosaurs the MT I, II and III have a well-developed ginglymoid distal articular surface (Colbert and Russell, 1969; Ostrom, 1969; Norell and Makovicky, 1997, 1999; Fowler et al. 2011). This could indicate that the first phalanges flexed and extended predominantly in a single plane (Fowler et al. 2011). Instead, in unenlagiines the ginglymoid distal facet of the MT II and III is less developed, so Ph. II-1 and III-1 moved in a predominantly vertical plane, although probably with some degree of sideways movement. The distal surface of MT I of unenlagiines is either ball-shaped, as in Buitreraptor (MPCA 238, Gianechini et al. 2018; Novas et al. 2018) and Rahonavis (FMNH PR 2830) or it is slightly ginglymoid, as in Neuquenraptor (Novas and Pol, 2005; Brissón Egli et al. 2017). Thus, in Neuquenraptor, the range of movement was probably more similar to that of digit I of eudromaeosaurs, whereas in Buitreraptor and Rahonavis digit I could have had a greater motion range. The more restricted range of digital motion in eudromaeosaurs is further emphasized by the more ginglymoid interphalangeal articulations in comparison with those of unenlagiines. This morphology could give the digits a greater resistance to torsional stress, thus preventing disarticulation of the joints during manipulation of the prey with a greater grasping force (Fowler et al. 2011). The distal facet of MT IV is generally more rounded in dromaeosaurids, which matches with the concave proximal articular facet of Ph. IV-1. This trait possibly indicates more freedom of movement for digit IV (Fowler et al. 2011). Thus, unenlagiines had the capacity to oppose pedal digits between them in a way similar to Deinonychus (Fowler et al. 2011). Digits I and IV probably had a wide range of motion, which would have allowed these digits to converge during flexion, thus achieving a grip position.

\subsubsection{Functional implications related to qualitative aspects of the pedal phalanges}

From the point of view of qualitative aspects, the digit II of unenlagiines is modified in a similar way to that of eudromaeosaurs, although important differences can be observed. First, in unenlagiines such as Buitreraptor, Neuquenraptor and Unenlagia paynemili (MUCPv 1066), the distal articular surface of phalanx II-2 is less proximally extended. This feature restricts the extension of the ungual phalanx, as can be observed in an isolated articulated digit II of Buitreraptor (MPCA 478, Gianechini et al. 2018), in which the ungual seems to be totally extended (Fig. 10). In Deinonychus and Bambiraptor this articular surface is more proximally extended (F.A.G., personal observation of YPM 5205 and AMNH FR 30556), and thus the claw had the possibility of a greater extension (see Senter, 2009). Additionally, the phalanges of digit II of eudromaeosaurs are more robust than those of unenlagiines. This digit is the main one implied in the predatory function, so a robust digit II in eudromaeosaurs could be advantageous in capturing and subduing large prey. Moreover, eudromaeosaurs have a short Ph. II-1. This phalanx represents part of the out-lever of the flexor muscle of the digit (possibly the M. flexor perforatus digiti II, which probably was inserted onto the proximoventral zone of the phalanx as in extant birds; Hudson, 1937; Vanden Berge and Zweers, 1993). Thus, the shortness of Ph. Il-1 could maximize the mechanical advantage of the flexor muscle and the grasping strength of the digit II. Another difference is the more proximally extended proximoventral heel of phalanx II-2 of eudromaeosaurs, which possibly was an insertion point of flexor muscles (Ostrom, 1969).

The mentioned characters of the digit II of the eudromaeosaurs seem to indicate the capacity to exert stronger predatory efforts, which could be an advantageous feature for subduing large prey. Conversely, the phalangeal morphology of unenlagiines would indicate weak predatory efforts. Moreover, the longer Ph. II-1 of unenlagiines also suggests faster movements of digit II, which could be eventually useful for hunting small prey.

Differences in the degree of development and curvature of the claw of digit II between eudromaeosaurs and unenlagiines are difficult to evaluate, mainly because most unenlagiines have not preserved a complete ungual. The available data (Table S3) do not contain clear evidence indicating that eudromaeosaurs have a more developed and more curved ungual than unenlagiines.

Another possible difference between unenlagiines and eudromaeosaurs concerns the position of digit I, which might have some implications for a potential grasping function. For instance, in Deinonychus, digit I is articulated at mid-length of the diaphysis of MT II (Ostrom, 1969; Fowler et al. 2011), suggesting it would have closed over the posterior face of the metatarsus during flexion. Moreover, previous authors proposed that in this taxon the metatarsus would have been positioned semi-horizontally while the 
(a)

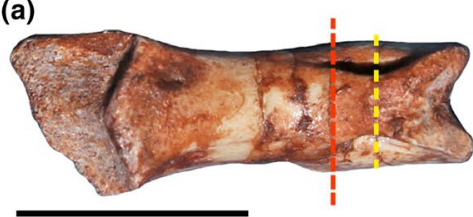

(b)

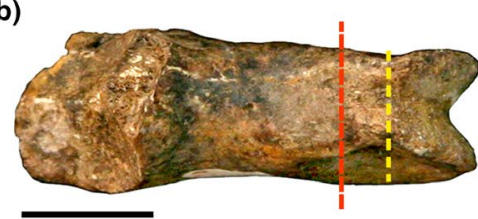

(c)

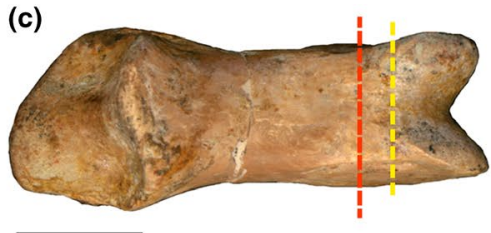

(d)

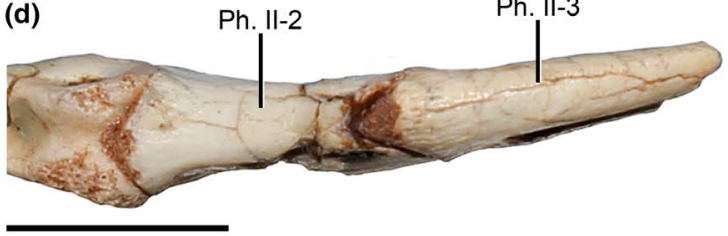

(e)

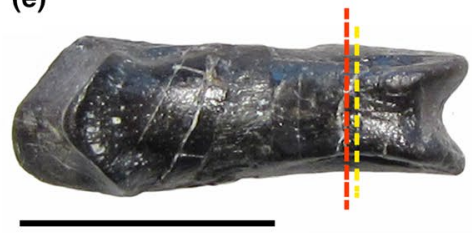

(f)

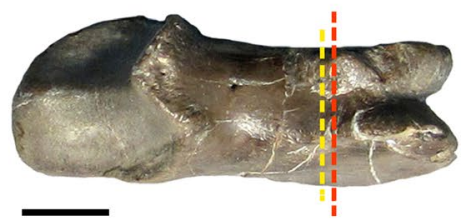

FIGURE 10 Comparisons between pedal phalanges II-2 of unenlagiines, Bambiraptor, and the eudromaeosaur Deinonychus, in dorsal view. The red dotted line indicates the posterior limit of the collateral ligament pit and the yellow dotted line indicates the posterior limit of the distal articular facet. (a) Buitreraptor gonzalezorum (MPCA 238). (b) Neuquenraptor argentinus (MCF PVPH 77). (c) Unenlagia paynemili (MUCPV 1066). (d) Articulated phalanges II-1, II-2 and II-3 of Buitreraptor gonzalezorum (MPCA 478) (the ungual phalanx is totally extended, so that the proximal extent of the articular surface is shown). (e) Bambiraptor feinbergorum (AMNH FR 30556). (f) Deinonychus antirrhopus (YPM 5205). Scale bars $=1 \mathrm{~cm}$. (f) is courtesy of the Division of Vertebrate Paleontology; YPM VP.005205, Peabody Museum of Natural History, Yale University, New Haven, Connecticut, USA; peabody.yale.edu; photography by Federico A. Gianechini

animal was subduing its prey and thus helped in restraining it (Fowler et al. 2011). Among unenlagiines, only one specimen of Buitreraptor (MPCN-PV-598) preserves a complete and articulated foot. In this specimen, digit I seems to be located in the original position, articulated to the medial and distal surface of MT II (Novas et al. 2018). Thus, it was not necessary for the metatarsal to be placed in a semi-horizontal position for digit I to participate in gripping the prey.

\subsection{5 | Morphological and functional correlates in extant raptorial birds and possible resemblances with dromaeosaurids}

An interesting convergence is observed in the morphospace of the long bone measurements between extant raptorial birds and some eudromaeosaurs. Both groups tend to show positive PPC2 values (Fig. 2), as they have relatively long femora and consequently shorter metatarsi. Moreover, raptorial birds converge specifically with Deinonychus and Velociraptor in the presence of wider metatarsi, as reflected by their fewer negative values in the PPC1. In general, in extant raptorial birds a shorter and robust metatarsus is related to the ability of the foot to exert a greater grip force. By contrast, a longer metatarsus is correlated with a minor grip force although it supports the capacity for rapid movement (Ward et al. 2002; Zeffer et al. 2003; Einoder and Richardson, 2007; Habib and Ruff, 2008; Fowler et al. 2009, 2011). In a general way, owls (Strigiformes) have the shortest and most robust metatarsus, whereas falconiforms and especially accipitrids have a longer and more slender metatarsus (Ward et al. 2002; Einoder and Richardson, 2007; Fowler et al. 2009). Thus, owls have a greater grip capacity and strength, although these abilities are also related to other characters of the foot, such as the presence of sesamoids, a specialized tendon-locking mechanism, and a facultative zygodactyl condition (Ward et al. 2002; Einoder and Richardson, 2007; Fowler et al. 2009). Among the raptorial birds included in our analyses, Milvago and Polyborus (falconiforms of the subfamily Polyborinae) are characterized by longer and slender tarsometatarsus when compared with accipitrids (i.e. Geranoaetus and Elanus). This could indicate greater cursorial capacities, consistent with suggestions by previous authors (Mosto et al. 2013).

Similarly, the short and robust metatarsus of eudromaeosaurs, such as Velociraptor and Deinonychus, could have allowed a great grip force (Ostrom, 1969; Fowler et al. 2011). By contrast, the elongated subarctometatarsus of unenlagiines could have allowed a greater capacity of rapid movement, like in falconiforms and accipitrids, although it could have reduced grip strength (Fowler et al. 2011).

Although certain morphological and even functional features can be compared among these dromaeosaurids and extant raptorial birds, it must be also considered that these birds are predominantly aerial with a generally limited terrestrial locomotion (but see Mosto et al. 2013). Raptorial birds share many features of the autopodium, e.g. elongation of the distal non-ungual phalanges, independently of their specific type of prey and the hunting method they employ. This can be interpreted as the result of a predominant influence of hunting and grasping specializations, instead of terrestrial locomotion (Eyton, 1867; Fisher, 1946; Hopson, 2001; Kambic, 2008; Kavanagh et al. 2013). Conversely, dromaeosaurids had a terrestrial locomotion, although a partially or primarily arboreal habitat has been suggested for some taxa (Chatterjee, 1997; Manning et al. 2006, 2009). So, it is to be expected that both factors of selective pressures, i.e. predation and terrestrial locomotion, had a great influence on their hindlimb and autopodium. This is a main reason behind the segregation between extant birds and dromaeosaurids in the morphospace. Also it might 
explain the presence of elongated distal phalanges in dromaeosaurids, although not as strikingly long as those of extant raptorial birds [see also the study by Kavanagh et al. (2013) on the modular evolution of proportions of the pedal phalanges]. To conclude, differences in hindlimb morphology and proportions between eudromaeosaurs and unenlagiines can be considered by mainly focusing on these partially antagonist specializations. The morphological design of the eudromaeosaurs autopodia indicates a more marked specialization to a predatory habit, whereas in unenlagiines a more marked cursorial specialization would have occurred.

\subsection{Locomotor and predatory habits of Buitreraptor and other unenlagiines}

Based on the previous discussion, unenlagiines possibly had a better cursorial locomotor performance and the capacity to reach greater running velocities than eudromaeosaurs. Of course, this does not mean that eudromaeosaurs did not have an effective locomotion and the ability to run fast. Possibly, eudromaeosaurs may have made sudden bursts of runs at high speed, but for shorter periods of time and/or for short distances, whereas unenlagiines could have maintained an accelerated pace for longer time and/or distance. The metatarsus of eudromaeosaurs has a structure with functional adaptations possibly more useful to effective predation than to cursorial locomotion. The morphological differences of the pedal phalanges between the two groups, especially those of digit II, could be more directly related to different predatory habits.

It is remarkable that the metapodium had a great morphological plasticity along the evolution of dromaeosaurids. Its structure differs drastically between unenlagiines and eudromaeosaurs (and microraptorines, which also have a subarctometatarsalian condition), depending on the relative and differential importance of the mechanical benefits associated both with predatory and locomotor functions. By contrast, as the results of the phylogenetic PCA indicate, the length proportions of the phalanges are not meaningfully dissimilar between these groups. A probable explanation for this is that the phalanges are the main elements implied in predatory functions. Consequently, the predatory habit exerted a greater selective pressure on the morphology of the phalanges, regardless of the particular feeding strategy (i.e. the way of hunting the prey) and locomotor habit of the taxa concerned. Nevertheless, some specific differences observed in unenlagiines are remarkable, such as the longer and slender phalanx II-1 (as the phylogenetic PCA indicates), and the greater freedom of movement of the remaining digits (which can be inferred from the interphalangeal articular morphology). These features could have allowed unenlagiines a fast and secure grip of small and agile/elusive prey that did not demand great efforts to be subdued.

Unenlagiines and microraptorines have similar modifications of the metapodium, and thus they probably had a similar mode of moving on the ground, except the capacity of gliding postulated for some microraptorines (Xu et al. 2003; Chatterjee and
Templin, 2007; Alexander et al. 2010). Probably, these two groups of dromaeosaurids used digit II for predation, although their predatory habits, i.e. the way of hunting and the type of prey, were not necessarily the same. Notably, some microraptorines (at least Microraptor and Sinornithosaurus) have a phalanx II-1 shorter than II-2 (Appendix S1), as in eudromaeosaurs. Additionally, some specimens of Microraptor gui indicate it fed on mammals, enantiornithine birds and fishes, which is evidence for diversified feeding habits and for their ability to exploit different ecological niches on ground, trees and water (Larsson et al. 2010; O'Connor et al. 2011; Xing et al. 2013).

It is likely that unenlagiines preyed on rapid and elusive animals, although it is difficult to know more specifically the type of prey that they hunted. In addition, there is no direct evidence of their feeding habits, such as the gut content of the Microraptor specimens. Nevertheless, it is possible to achieve an approximation of the feeding habits of unenlagiines, especially for the better represented taxa such as Buitreraptor. Regarding other unenlagiines the available information is more scarce, so it is more difficult to infer whether they differed in their predatory strategies or the type of prey they hunted.

Based on the small size, slender proportions (especially those of metapodium), and the inferred cursorial capacities of Buitreraptor, it probably foraged on the ground searching small prey, such as invertebrates, reptiles or mammals, over large distances and probably employing high-speed pursuits in some cases. The fauna recorded from the fossiliferous area of La Buitrera, where Buitreraptor was discovered, also includes remains of small tetrapods such as snakes, sphenodonts, crocodyliforms and mammals (Carignano et al. 2002; Apesteguía and Novas, 2003; Pol and Apesteguía, 2005; Apesteguía and Zaher, 2006; Rougier et al. 2011), which could have been potential prey items. Buitreraptor would have employed its pes to subjugate and immobilize the captured animal. The fast movements and curved enlarged claw of digit II would have helped this function, eventually causing serious injuries or even death of the prey.

Another reliable indicator of the type of diet and feeding strategy is the dental morphology. The teeth of Buitreraptor are numerous, tiny, lateromedially compressed, and devoid of denticles (Gianechini et al. 2011). Instead, eudromaeosaurs are generally characterized by larger serrated teeth, such as those seen in Dromaeosaurus, Deinonychus, Velociraptor, Saurornitholestes and Tsaagan (Colbert and Russell, 1969; Ostrom, 1969; Currie, 1995; Barsbold and Osmólska, 1999; Norell et al. 2006; Turner et al. 2012), although many taxa have denticles only on the distal carina. Such a dentition would have allowed ingestion of larger prey or tearing and cutting the flesh from them into smaller pieces. Feeding models have been proposed for some taxa, such as Deinonychus (Fowler et al. 2011), although they are difficult to apply to Buitreraptor because the size of the teeth and their lack of denticles. Buitreraptor did not have other flesh-tearing structures (e.g. the tomial tooth of extant raptorial birds), so it is very likely that it consumed whole small animals and that the 
teeth were mainly employed as a tool to hold them. Also, it is possible that these teeth have been used to tear apart small prey, in order to consume them in more than one swallow. In previous works, it has been postulated that the dentition of Buitreraptor would indicate a piscivorous feeding mode (Gianechini et al 2011). Certainly, Microraptor also had small non-serrated teeth and there is evidence that it fed on fish. However, this unique feature is not a reliable indicator of a strict piscivorous diet, since other morphological evidence must also be taken into account. Moreover, Microraptor included in its diet other animals in ad dition to fish, as mentioned above. Buitreraptor is also characterized by having long forelimbs and hands (Agnolín and Novas, 2013; Novas et al. 2018), which could also have used to handle the prey once it was captured and subjugated with the feet.

Extant long-legged and predominantly terrestrial birds that forage on the ground and hunt small prey include the seriemas (Cariamiformes) and the Secretary Bird (Falconiformes). The Secretary Bird kicks and stamps on the prey until it is wounded or incapacitated, and then takes it with its beak (Kemp and Kemp, 1978; Kemp, 1995; Portugal et al. 2016). By contrast, the Red-legged Seriema (Cariama cristata) takes the prey with its beak and hits it on the ground with sudden movements of the head until it is injured (Boyle, 1917). An interesting trait of this seriema species is that it has a markedly curved ungual phalanx on the second digit (Burmeister, 1937; Jones, 2010; F.A.G., personal observation of MACN 23873). Some authors proposed that this bird uses its enlarged claw to hold the prey against the ground, although others do not agree (Gonzaga, 1996, and references therein). The extinct phorusrhacids were terrestrial, generally flightless carnivorous birds, which are also characterized by having a markedly developed and curved ungual of the second digit (Sinclair and Farr, 1932; Alvarenga and Höfling, 2003; Jones, 2010). Some authors have proposed that this claw could be used as a means of apprehending the prey on the substrate, before using the beak to tear it apart (Jones, 2010). Buitreraptor could have used its pedal claw in a way similar to that proposed for seriemas and phorusrhacids, although there is no direct evidence for this.

Other unenlagiines, such as Austroraptor, probably used a strategy of hunting and subjection of the prey similar to that of Buitreraptor. Although Austroraptor is significantly larger (estimated total length: $5 \mathrm{~m}$ ), it has numerous, non-serrated, and small teeth in comparison with the size of the skull (Novas et al. 2009 Gianechini et al. 2011, 2017; Gianechini, 2014). However, the teeth of Austroraptor are conical, so they probably were more resistant and could have been employed to seize and dismember large prey. Austroraptor probably had length proportions of the hindlimb bones similar to those of Buitreraptor. Also it had a subarctometatarsalian condition, suggesting potentially good cursorial abilities. However, Austroraptor had strikingly shorter arms compared to other unenlagiines, so it would not have used them to manipulate the prey, or at least not in the same way that Buitreraptor.

Rahonavis was probably a less cursorial taxon due to its hindlimb morphology. However, it had a relatively long tibia, so fast
SOCIETY

chases of prey cannot be ruled out as a hunting strategy used by this taxon. Moreover, Rahonavis has a digit II similar to that of other unenlagiines, so it probably had similar functional capacities. Nevertheless, the distal phalanges are shorter than in other unenlagiines, so it probably had slightly lower gripping abilities. Unfortunately, cranial remains and teeth of Rahonavis are unknown, so it is more difficult to speculate about the type and size of animals that it could have been preyed upon. Surely it fed on small prey, although is not possible to know if it was able to tear flesh from larger prey.

For Rahonavis an arboreal habit can be proposed, based on its small size and the, albeit weak, grasping ability of its autopodium. Many extant birds with grasping abilities of the foot are 'perchers' and have this habit, i.e. they are predominantly arboreal foragers (Glen and Bennet, 2007). Furthermore, this type of lifestyle is correlated in paravians with aerial locomotor capacities. Rahonavis shows evidence of feathered forelimbs (Forster et al. 1998) and many osteological traits that suggest the capacity for flapping flight (Agnolín and Novas, 2013). Also, the claw of pedal digit II has been considered as a potential tool for climbing trees (Chatterjee, 1997; Manning et al. 2006, 2009). For Buitreraptor a similar lifestyle could be suggested, mainly considering its small size. However, the proportions of the hindlimb of Buitreraptor and also its subarctometatarsalian condition are probably more related to a terrestrial habit than to an arboreal one. Additionally, it is important to take into account the paleoenvironment in which it lived. Buitreraptor was found in deposits that indicate a mainly aeolian environment and the existence of a large desert (Candia Halupczok et al. 2016a; Apesteguía et al. 2016b; Candia Halupczok et al. 2016b; Candia Halupczok et al. 2018), where trees were probably very scarce or non-existent. Meanwhile, other unenlagiines such as Neuquenraptor, Unenlagia comahuensis, Unenlagia paynemili and Austroraptor had large body sizes, so an arboreal habit for them is difficult to envision. Furthermore, previous authors considered that aerodynamic features were lost in large-sized dromaeosaurids, as suggested by the scarce development or else lack of papillae for feather attachment on their ulna (Turner et al. 2007).

The specimens of Neuquenraptor, $U$. comahuensis and $U$. paynemili are much more fragmentary than those of other unenlagiines, as for example none of them have cranial remains, and thus attempts to infer the habits of these taxa represents a greater challenge. However, in the case of Neuquenraptor the features of its hindlimb indicate that velocity was probably important to obtain its prey. Only scarce hindlimb remains are known for U. comahuensis and $U$. paynemili, including the phalanges of digit II, which are very similar to those of the other unenlagiines (Novas and Puerta, 1997; Calvo et al. 2004; Gianechini and Apesteguía, 2011; Porfiri et al. 2011). Accordingly, mainly due to the lack of skull and metatarsus remains, as well as of most of the pedal phalanges, it is more difficult to infer locomotor and predatory habits of $U$. comahuensis and U. paynemili. 


\section{5 | CONCLUSION}

In conclusion, morphological differences between the hindlimbs of unenlagiines and eudromaeosaurs reflect differences both in locomotor and in predatory habits. In unenlagiines the presence of a long tibia and of a long, slender and subarctometatarsalian metatarsus suggests greater cursorial capacities with respect to eudromaeosaurs. Conversely, eudromaeosaurs have a shorter, wider and non-subarctometatarsalian metatarsus. The two groups of dromaeosaurids have similar length proportions of the pedal digits, and share the elongation of the distal pedal phalanges, the latter feature probably allowing them the ability to grasp. However, certain morphological traits of eudromaeosaurs, such as a more robust metatarsus, markedly ginglymoid distal articular surfaces of metatarsals I, II and III, as well as interphalangeal articular surfaces, and a shorter phalanx II-1, indicate that these dromaeosaurids possibly exerted higher grip strength than unenlagiines. By contrast, foot proportions and slenderness of unenlagiines would not have allowed them to perform high-force grasping. Instead, unenlagiines may have been able to make faster movements with both the metatarsus and the digit II. Comparable morphofunctional difference is analogously observed in extant raptorial birds. Those taxa with the shortest metatarsi, such as owls, have the ability to produce the greatest grip force. By contrast, taxa with longer metatarsi, such as polyborine falconiforms, generate a lesser grip force but can effect faster movements with the pes.

The morphological differences between the pedal phalanges of unenlagiines and eudromaeosaurs are not as drastic as those observed between their metatarsi. This fact, together with the similar length proportions of the pedal phalanges, seems to indicate that the morphology of these pedal elements varied to a small extent along dromaeosaurid evolution. Since the digits were the main parts of the autopodium involved in the predatory function it is probable that the predatory habit exerted a greater selective pressure on the morphology of the phalanges.

Buitreraptor gonzalezorum, with its small size, high cursorial capacities, a long metatarsus and phalanx II-1, more mobile phalanges, and tiny teeth, was probably a terrestrial predator that preyed on small elusive animals, such as arthropods, lizards and mammals, using rapid gripping movements of its pes. Rahonavis ostromi was also a small-sized unenlagiine, although its morphology seems to indicate that it had less well-developed cursorial abilities. On the other hand, its small body size and potential climbing and aerial locomotion capacities could be related to an arboreal habit. Other unenlagiines, such as the large-sized Austroraptor cabazai and the medium-sized Neuquenraptor argentinus probably preyed on larger animals, also making use of their well-developed cursorial faculties. U. comahuensis and U. paynemili are more fragmentary and so it is more difficult to infer a locomotor and predatory habit for them.

During dromaeosaurid evolution, the different lineages seem to have diverged acquiring varied lifestyles, as documented by unenlagiines, microraptorines, eudromaeosaurs, and recently by halszkaraptorines (Cau et al. 2017, although also see Brownstein, 2019). Future studies, such as reconstructions of the muscular system, will be necessary to analyse the hindlimb as an osteo-muscular integrated complex, and the ways it would have been involved both in locomotion and predation in dromaeosaurids. These paleobiological aspects will contribute to a better comprehension of the dromaeosaurid evolutionary story, as well as about the role of these theropods within the ecosystems in which they lived.

\section{INSTITUTIONAL ABBREVIATIONS}

Below is a list of the institutional abbreviations used in the present paper.

AMNH FR, American Museum of Natural History, New York, NY, USA; CFA-OR, Fundación de Historia Natural 'Félix de Azara', Ciudad Autónoma de Buenos Aires, Argentina; FMNH PR, Field Museum of Natural History, Chicago, IL, USA; MACN, Museo Argentino de Ciencias Naturales 'Bernardino Rivadavia', Ciudad Autónoma de Buenos Aires, Argentina; MCF PVPH, Museo 'Carmen Funes', Plaza Huincul, Neuquén, Argentina; MML, Museo Municipal de Lamarque, Lamarque, Río Negro, Argentina; MPCA, Museo Provincial 'Carlos Ameghino', Cipolletti, Río Negro, Argentina; MPCN-PV, Museo Patagónico de Ciencias Naturales, General Roca, Río Negro, Argentina; MUCPv, Museo de Geología y Paleontología de la Universidad Nacional del Comahue, Neuquén, Argentina; YPM, Yale Peabody Museum, New Haven, CT, USA.

\section{ACKNOWLEDGEMENTS}

We thank the curators of different institutions, who kindly allowed us access to the materials from collections under their care: Pablo Tubaro, Darío Lijtmaer and Yolanda Davies, from the División de Ornitología, MACN, Buenos Aires, Argentina; Sergio Bogan, from the Fundación de Historia Natural 'Félix de Azara', Universidad Maimónides, Buenos Aires, Argentina; Daniel Cabaza, from the MML, Río Negro, Argentina; Carlos Muñoz, from the MPCA, Cipolletti, Río Negro, Argentina; Pablo Chafrat, from the MPCN, General Roca, Río Negro, Argentina; Daniel Brinkman, from the YPM, Connecticut, USA, and Carl Mehling, from the AMNH, New York, USA. We also thank Washington Jones for sharing kindly information and bibliography about phorusrhacids and seriemas, and Nestor Toledo for sharing his ideas about functional aspects of tetrapod hindlimb. Andrea Arcucci made several contributions to improve the redaction and orthography of the manuscript. She, together with Guillermina Giordano, Bárbara Espeche and María A. Gómez also contributed with valuable comments about theoretical aspects. The revisions and helpful comments of Sara Burch and an anonymous reviewer improved the quality of the manuscript. The realization of this work was possible by the financing of the Agencia Nacional de Promoción Científica y Tecnológica (PICT 2014-1449), the Secretaría de Ciencia y Tecnología UNSL (PROICO 2-0618), The Jurassic Foundation, and the American Museum of Natural History Collection Study Grant Program to FAG, and CONICET to F.A.G., M.D.E. and I.D.M. 


\section{ORCID}

Federico A. Gianechini iD https://orcid.org/0000-0002-0220-9487 Marcos D. Ercoli iD https://orcid.org/0000-0003-2695-2723

\section{REFERENCES}

Abourachid, A. and Renous, S. (2000) Bipedal locomotion in ratites (Paleognatiform): examples of cursorial birds. Ibis, 142, 538-549.

Agnolín, F.L. and Novas, F.E. (2011) Unenlagiid theropods: are they members of the Dromaeosauridae (Theropoda, Maniraptora)? Anais da Academia Brasileira de Ciências, 83, 117-162.

Agnolín, F.L. and Novas, F.E. (2013) Avian Ancestors: A Review of the Phylogenetic Relationships of the Theropods Unenlagiidae, Microraptoria Anchiornis and Scansoriopterygidae. Dordrecht: Springer.

Alexander, D.E., Gong, E., Martin, L.D. et al. (2010) Model tests of gliding with different hindwing configurations in the four-winged dromaeosaurids Microraptor gui. Proceedings of the National Academy of Sciences of the United States of America, 107, 2972-2976.

Alvarenga, H. and Höfling, E. (2003) Systematic revision of the Phorusrhacidae (Aves: Ralliformes). Papéis Avulsos de Zoologia (São Paulo), 43, 55-91.

Apesteguía, S. and Novas, F.E. (2003) Late Cretaceous sphenodontian from Patagonia provides insight into lepidosaur evolution in Gondwana. Nature, 425, 609-612.

Apesteguía, S. and Zaher, H. (2006) A Cretaceous terrestrial snake with robust hindlimbs and a sacrum. Nature, 440, 1037-1040.

Apesteguía, S., Smith, N.D., Juárez Valieri, R. et al. (2016a) An unusual new theropod with a didactyl manus from the Upper Cretaceous of Patagonia, Argentina. PLoS ONE, 7, e0157793. Available at: https:// doi.org/10.1371/journal.pone.0157793.

Apesteguía, S., Veiga, G.D., Sánchez, M.L. et al. (2016b) Kokorkom, el desierto de los huesos: grandes dunas eólicas en la Formación Candeleros (Cretácico Superior). Patagonia Argentina. Ameghiniana, 54(Suppl), 7.

Barsbold, R. (1983) Carnivorous dinosaurs from the Late Cretaceous of Mongolia. Sovmestnaya Sovetsko-Mongol'skaya Paleontologicheskaya Ekspiditsiya Trudy, 19, 1-119. [in Russian]

Barsbold, R. and Osmólska, H. (1999) The skull of Velociraptor (Theropoda) from the Late Cretaceous of Mongolia. Acta Palaeontologica Polonica, 44, 189-219.

Blomberg, S.P., Garland, T. Jr and Ives, A.R. (2003) Testing for phylogenetic signal in comparative data: behavioral traits are more labile. Evolution, 57, 717-745

Bonaparte, J.F. (1999) Tetrapod faunas from South America and India: a palaeobiogeographic interpretation. Proceedings of the Indian National Science Academy, 65, 427-437.

Boyle, H.S. (1917) Field notes on the seriema (Chunga burmeisteri). The Auk, 34, 294-296.

Brissón Egli, F., Aranciaga Rolando, A.M., Agnolín, F.L. and Novas, F. (2017) Osteology of the unenlagiid theropod Neuquenraptor argentinus from the Late Cretaceous of Patagonia. Acta Palaeontologica Polonica, 62 549-562. Available at: https://doi.org/10.4202/app.00348.2017.

Brownstein, C.D. (2019) Halszkaraptor escuilliei and the evolution of the paravian bauplan. Scientific Reports, 9, 16455. Available at: https:// doi.org/10.1038/s41598-019-52867-2

Brusatte, S.L., Vremir, M., Csiki-Sava, Z. et al. (2013) The osteology of Balaur bondoc, an island-dwelling dromaeosaurid (Dinosauria: Theropoda) from the Late Cretaceous of Romania. Bulletin of the American Museum of Natural History, 374, 1-100.

Bunce, M., Worthy, T.H., Phillips, M.J. et al. (2009) The evolutionary history of the extinct ratite moa and New Zealand Neogene paleogeography. Proceedings of the National Academy of Sciences of the United States of America, 106, 20646-20651.

Burmeister, H.C. (1937) Contribução para a historia natural da seriema. Rev Mus Paulista, 32, 35-152.
Burnham, D.A. et al. (2004) New information on Bambiraptor feinbergi (Theropoda: Dromaeosauridae) from the Late Cretaceous of Montana. In: Currie, P.J., Koppelhus, E.B. and Shugar, M.A. (Eds.) Feathered Dragons. Bloomington: Indiana University Press, pp. 67-111.

Burnham, D.A., Derstler, K.L., Currie, P.J. et al. (2000) Remarkable new birdlike dinosaur (Theropoda: Maniraptora) from the Upper Cretaceous of Montana. Univ Kans Paleontol Contrib, 13, 1-14.

Calvo, J.O., Porfiri, J.D. and Kellner, A.W.A. (2004) On a new maniraptoran dinosaur (Theropoda) from the Upper Cretaceous of Neuquén, Patagonia, Argentina. Arquivos do Museu Nacional, 62, 549-566.

Candia Halupczok, D.J., Sánchez, M.L., Veiga, G.D. et al. (2018) Dinosaur tracks in the Kokorkom Desert, Candeleros Formation (Cenomanian, Upper Cretaceous), Patagonia Argentina: implications for deformation structures in dune fields. Cretaceous Res, 83, 194-206. Available at: https://doi.org/10.1016/j.cretres.2017.10.017.

Candia Halupczok, D.J., Sánchez, M.L. and Veiga, G.D. et al. (2016a) Depósitoslacustres en sucesiones eólicas enelyacimiento paleontológico La Buitrera: Una contribución al conocimiento paleoambiental de la Formación Candeleros (Cretácico Superior). VII Congreso Latinoamericano de Sedimentología-XV Reunión Argentina de Sedimentología, Santa Rosa La Pampa, Argentina. September 2016, Abstracts Book, 49.

Candia Halupczok, D.J.,Sánchez, M.L.andVeiga, G.D.etal.(2016b) Evolución de paleodesiertos en la Formación Candeleros (Grupo NeuquénCretácico Superior), Cuenca Neuquina. VII Congreso Latinoamericano de Sedimentología-XV Reunión Argentina de Sedimentología, Santa Rosa, La Pampa, Argentina, September 2016, Abstracts Book, 50.

Carignano, A.P., Pol, D., Apesteguía, S. et al. (2002) La diversidad de cocodrilos de "La Buitrera" (Fm. Candeleros), Provincia de Río Negro. Ameghiniana, 39(Suppl), 7R.

Carrano, M.T. (1999) What, if anything, is a cursor? Categories versus continua for determining locomotor habit in mammals and dinosaurs. Journal of Zoology, 247, 29-42.

Carrano, M.T., Benson, R.B.J. and Sampson, S.D. (2012) The phylog eny of Tetanurae (Dinosauria: Theropoda). Journal of Systematic Palaeontology, 10, 211-300.

Cau, A., Beyrand, V., Voeten, D.F.A.E. et al. (2017) Synchrotron scanning reveals amphibious ecomorphology in a new clade of bird-like dinosaurs. Nature, 552, 395-399. Available at: https://doi.org/10.1038/ nature 24679

Chatterjee, S. (1997) The Rise of Birds: 225 Million Years of Evolution. London: The John Hopkins Press Ltd.

Chatterjee, S. and Templin, R.J. (2007) Biplane wing planform and flight performance of the feathered dinosaur Microraptor gui. Proceedings of the National Academy of Sciences of the United States of America, 104, 1576-1580.

Colbert, E.H. and Russell, D.A. (1969) The small Cretaceous dinosaur Dromaeosaurus. American Museum Novitates, 2380, 1-49.

Coombs, W.P. Jr (1978) Theoretical aspects of cursorial adaptations in dinosaurs. The Quarterly Review of Biology, 53, 393-418.

Currie, P.J. (1995) New information of the anatomy and relationships of Dromaeosaurus albertensis (Dinosauria: Theropoda). Journal of Vertebrate Paleontology, 15, 576-591.

Currie, P.J., Funston, G.F. and Osmólska, H. (2016) New specimens of the crested theropod dinosaur Elmisaurus rarus from Mongolia. Acta Palaeontologica Polonica, 61, 143-157.

Currie, P.J. and Paulina Carabajal, A. (2012) A new specimen of Austroraptor cabazai Novas, Pol, Canale, Porfiri and Calvo, 2008 (Dinosauria, Theropoda, Unenlagiidae) from the Latest Cretaceous (Maastrichtian) of Río Negro, Argentina. Ameghiniana, 49, 662-667. Available at: https://doi.org/10.5710/amgh.30.8.2012.574.

Development Core Team, R. (2018) R: a language and environment for statistical computing. Vienna: $\mathrm{R}$ Foundation for Statistical Computing. Available at: http://www.r-project.org. [Accessed 15 May 2018]. 
Revell, L.J. (2009) Size-correction and principal components for interspecific comparative studies. Evolution, 63, 3258-3268.

Degrange, F.J. (2017) Hind limb morphometry of terror birds (Aves, Cariamiformes, Phorusrhacidae): functional implications for substrate preferences and locomotor lifestyle. Earth and Environmental Science Transactions of The Royal Society of Edinburgh, 106, 257-276.

Einoder, L. and Richardson, A. (2007) Aspects of the hindlimb morphology of some Australasian birds of prey: a comparative and quantitative study. The Auk, 124, 773-788.

Eyton, T.C. (1867) Osteologia Avium; or, A Sketch of the Osteology of Birds. Wellington, Salop: R. Hobson.

Farlow, J.O., Gatesy, S.M., Holtz, T.R. Jr et al. (2000) Theropod Locomotion. American Zoologist, 40, 640-663.

Fisher, H.I. (1946) Adaptations and comparative anatomy of the locomotor apparatus of New World vultures. American Midland Naturalist, 35, 545-727.

Forster, C.A., Sampson, S.D., Chiappe, L.M. et al. (1998) The theropod ancestry of birds, new evidence from the Late Cretaceous of Madagascar. Science, 279, 1915-1919.

Fowler, D.W., Freedman, E.A. and Scannella, J.B. (2009) Predatory functional morphology in raptors: interdigital variation in talon size is related to prey restraint and immobilisation technique. PLoS ONE, 4, e7999. Available at: https://doi.org/10.1371/journ al.pone.0007999.

Fowler, D.W., Freedman, E.A., Scannella, J.B. et al. (2011) The predatory ecology of Deinonychus and the origin of flapping in birds. PLoS ONE, 6, e28964. Available at: https://doi.org/10.1371/journ al.pone.0028964.

Funston, G.F., Currie, P.J., Eberth, D.A. et al. (2016) The first oviraptorosaur (Dinosauria: Theropoda) bonebed: evidence of gregarious behaviour in a maniraptoran theropod. Scientific Reports, 6, 35782. Available at: https://doi.org/10.1038/srep35782.

Gambaryan, P.P. (1974) How Mammals Run. New York: John Wiley \& Sons.

Gao, C., Morschhauser, E.M., Varricchio, D.J. et al. (2012) A second soundly sleeping dragon: new anatomical details of the chinese troodontid Mei long with implications for phylogeny and taphonomy. PLoS ONE, 7, e45203. Available at: https://doi.org/10.1371/journ al.pone.0045203.

Garland, T. Jr and Janis, C.M. (1993) Does metatarsal/femur ratio predict maximal running speed in cursorial mammals? Journal of Zoology, 229, 133-151.

Gatesy, S.M. and Middleton, K.M. (1997) Bipedalism, flight, and the evolution of theropod locomotor diversity. Journal of Vertebrate Paleontology, 17, 308-329.

Gianechini, F.A. (2014) Revisión de los Deinonychosauria (Dinosauria, Theropoda) de la Argentina: anatomía y filogenia. Ph.D. Thesis, Universidad de Buenos Aires, Argentina, 426 pp. Available at: http:// digital.bl.fcen.uba.ar/gsdl-282/cgi-bin/library.cgi?a $=d \& c=$ tesis $\& d=T e s i s$ 5516_Gianechini. [Accessed 11 February 2019].

Gianechini, F.A. and Apesteguía, S. (2011) Unenlagiinae revisited: dromaeosaurid theropods from South America. Anais da Academia Brasileira de Ciências, 83, 163-195.

Gianechini, F.A., Makovicky, P.J. and Apesteguía, S. (2011) The teeth of the unenlagiine theropod Buitreraptor from the Cretaceous of Patagonia, Argentina, and the unusual dentition of the Gondwanan dromaeosaurids. Acta Palaeontologica Polonica, 56, 279-290.

Gianechini, F.A., Makovicky, P.J. and Apesteguía, S. (2017) The cranial osteology of Buitreraptor gonzalezorum Makovicky, Apesteguía, and Agnolín, 2005 (Theropoda, Dromaeosauridae), from the Late Cretaceous of Patagonia, Argentina. Journal of Vertebrate Paleontology, 37, e1255639. Available at: https://doi.org/10.1080/02724 634.2017.1255639.

Gianechini, F.A., Makovicky, P.J., Apesteguía, S. et al. (2018) Postcranial skeletal anatomy of the holotype and referred specimens of Buitreraptor gonzalezorum Makovicky, Apesteguía and Agnolín
2005 (Theropoda, Dromaeosauridae), from the Late Cretaceous of Patagonia. PeerJ, 6, e4558. Available at: https://doi.org/10.7717/ peerj.4558.

Glen, C.L. and Bennet, M.B. (2007) Foraging modes of Mesozoic birds and non-avian theropods. Current Biology, 17, 911-912.

Gonzaga, L.P. (1996) Family Cariamidae (seriemas). In: del Hoyo, J., Elliot, A. and Sargatal, J. (Eds.) Handbook of the Birds of the World. Vol. 3, Barcelona: Lynx Edicions, pp. 234-239.

Gregory, W.K. (1912) Notes on the principles of quadrupedal locomotion and on the mechanism of the limbs in hoofed animals. Annals of the New York Academy of Sciences, 22, 287-294.

Habib, M.B. and Ruff, C.B. (2008) The effects of locomotion on the structural characteristics of avian limb bones. Zoological Journal of the Linnean Society, 153, 601-624.

Hackett, S.J., Kimball, R.T., Reddy, S. et al. (2008) A phylogenomic study of birds reveals their evolutionary history. Science, 320, 1763-1768.

Hartman, S., Mortimer, M., Wahl, W.R. et al. (2019) A new paravian dinosaur from the Late Jurassic of North America supports a late acquisition of avian flight. PeerJ, 7, e7247. https://doi.org/10.7717/ peerj.7247.

Hildebrand, M. (1982) Analysis of Vertebrate Structure, 2nd ed. New York: John Wiley \& Sons.

Hildebrand, M. et al. (1985) Walking and running. In: Hildebrand, M., Bramble, D.M., Liem, K.F., et al. (Eds.) Functional Vertebrate Morphology. Cambridge: Belknap, Harvard, pp. 38-57.

Hildebrand, M. (1988) Analysis of Vertebrate Structure. New York: John Wiley \& Sons.

Holtz, T.R. Jr (1994) The arctometatarsalian pes, an unusual structure of the metatarsus of Cretaceous Theropoda (Dinosauria: Saurischia). Journal of Vertebrate Paleontology, 14, 480-519.

Hopson, J.A. (2001) Ecomorphology of avian and nonavian theropod phalangeal proportions: Implications for the arboreal versus terrestrial origin of bird flight. In: Gauthier, J. and Gall, L.F. (Eds.) New Perspectives on the Origin and Early Evolution of Birds: Proceedings of the International Symposium in Honor of John H. Ostrom. New Haven: Peabody Museum of Natural History, Yale University, pp. 211-235.

Hudson, G.E. (1937) Studies on the muscles of the pelvic appendages in birds. American Midland Naturalist, 18, 1-108.

Hwang, S.H., Norell, M.A., Qiang, J. et al. (2002) New specimens of Microraptor zhaoianus (Theropoda: Dromaeosauridae) from Northeastern China. American Museum Novitates, 3381, 1-44.

Jones, W.W. (2010) Nuevos aportes sobre la paleobiología de los fororrácidos (Aves: Phorusrhacidae) basados en el análisis de estructuras biológicas. PhD. Thesis, PEDECIBA, Facultad de Ciencias, Universidad de la República, Montevideo, Uruguay, $213 \mathrm{pp}$.

Kambic, R.E. (2008) Multivariate analysis of avian and non-avian theropod pedal phalanges. M.S. Thesis. Montana State University, Bozeman, Montana, USA, $90 \mathrm{pp}$.

Karhu, A.A. and Rautian, A.S. (1996) A new family of Maniraptora (Dinosauria: Saurischia) from the Late Cretaceous of Mongolia. Paleontological Journal, 30, 583-592.

Kavanagh, K.D., Shoval, O., Winslow, B.B. et al. (2013) Developmental bias in the evolution of phalanges. Proceedings of the National Academy of Sciences of the United States of America, 110, 18190-18195.

Kembel, S.W., Cowan, P.D., Helmus, M.R. et al. (2010) Picante: R tools for integrating phylogenies and ecology. Bioinformatics, 6, 1463-1464.

Kemp, A.C. (1995) Aspects of the breeding biology and behaviour of the secretarybird Sagittarius serpentarius near Pretoria, South Africa. Ostrich: Journal of African Ornithology, 66, 61-68.

Kemp, M.I. and Kemp, A.C. (1978) Bucorvus and Sagittarius: two modes of terrestrial predation. In:Proceedings of the Symposium on African Predatory Birds.Kemp, A.C. (Ed.) Pretoria: Northern Transvaal Ornithological Society, pp. 13-16.

Kim, J.Y., Kim, K.S., Lockley, M.G. et al. (2008) New didactyl dinosaur footprints (Dromaeosauripus hamanensis ichnogen. et ichnosp. nov.) 
from the Early Cretaceous Haman Formation, south coast of Korea. Palaeogeography, Palaeoclimatology, Palaeoecology, 262, 72-78. Available at: https://doi.org/10.1016/j.palaeo.2008.02.003.

Kimball, R.T., Wang, N., Heimer-McGinn, V. et al. (2013) Identifying localized biases in large datasets: a case study using the avian tree of life. Molecular Phylogenetics and Evolution, 69, 1021-1032.

Kurzanov, S.M. (1981) An unusual theropod from the Upper Cretaceous of Mongolia. Trudy Sovm Sov-Mong Paleontol Eksped, 15, 39-49 [in Russian].

Larsson, H.C.E., Hone, D.W., Dececchi, T.A. et al. (2010) The winged non-avian dinosaur Microraptor fed on mammals: implications for the Jehol Biota ecosystem. Journal of Vertebrate Paleontology, 30, 114A.

Li, R., Lockley, M.G., Makovicky, P.J. et al. (2008) Behavioral and faunal implications of Early Cretaceous deinonychosaur trackways from China. Naturwissenschaften, 95, 185-191.

Livezey, B.C. and Zusi, R.L. (2007) Higher-order phylogeny of modern birds (Theropoda, Aves: Neornithes) based on comparative anatomy. II. Analysis and discussion. Zoological Journal of the Linnean Society, 149, 1-95.

Lockley, M.G., White, D., Kirkland, J. et al. (2004) Dinosaur tracks from the Cedar Mountain Formation (Lower Cretaceous), Arches National Park, Utah. Ichnos, 11, 285-293.

Longrich, N.R. and Currie, P.J. (2009) A microraptorine (DinosauriaDromaeosauridae) from the Late Cretaceous of North America. Proceedings of the National Academy of Sciences of the United States of America, 106, 5002-5007.

Losos, J.B. (2008) Phylogenetic niche conservatism, phylogenetic signal and the relationship between phylogenetic relatedness and ecological similarity among species. Ecology Letters, 11, 995-1007.

Lü, J. and Brusatte, S.L. (2015) A large, short-armed, winged dromaeosaurid (Dinosauria: Theropoda) from the Early Cretaceous of China and its implications for feather evolution. Scientific Reports, 5, 11775 Available at: https://doi.org/10.1038/srep11775.

Lü, J., Li, G., Kundrát, M. et al. (2017) High diversity of the Ganzhou Oviraptorid Fauna increased by a new "cassowary-like" crested species. Scientific Reports, 7, 6393. Available at: https://doi.org/10.1038/ s41598-017-05016-6.

Makovicky, P.J., Apesteguía, S. and Agnolín, F.L. (2005) The earliest dromaeosaurid theropod from South America. Nature, 437, 1007-1011.

Makovicky, P.J., Apesteguía, S. and Gianechini, F.A. (2012) A new coelurosaurian theropod from the La Buitrera fossil locality of Río Negro, Argentina. Fieldiana Life and Earth Sciences, 5, 90-98.

Makovicky, P.J., Apesteguía, S. and Gianechini, F.A. (2016) A new, almost complete specimen of Alnashetri cerropoliciensis (Dinosauria: Theropoda) impacts our understanding of alvarezsauroid evolution. Ameghiniana, 53(Suppl), 62.

Makovicky, P.J., Kobayashi, Y. and Currie, P.J. (2004) Ornithomimosauria. In: Weishampel, D.B., Dodson, P. and Osmólska, H. (Eds.) The Dinosauria. Berkeley: University of California Press, pp. 137-150.

Makovicky, P.J., Li, D., Gao, K.-Q. et al. (2010) A giant ornithomimosaur from the Early Cretaceous of China. Proceedings of the Royal Society B, 277, 191-198.

Manning, P.L., Payne, D., Pennicot, J. et al. (2006) Dinosaur killer claws or climbing crampons? Biology Letters, 2, 110-112.

Manning, P.L., Margetts, L., Johnson, M.R. et al. (2009) Biomechanics of dromaeosaurid dinosaur claws: application of $x$-ray microtomography, nanoindentation, and finite element analysis. Anatomical Record 292, 1397-1405.

Martins, E.P. and Hansen, T.F. (1997) Phylogenies and the comparative method: A general approach to incorporating phylogenetic information into the analysis of interspecific data. American Naturalist, 149, 646-667.

Mayr, G., Pohl, B., Hartman, S. et al. (2007) The tenth skeletal specimen of Archaeopteryx. Zoological Journal of the Linnean Society, 149, 97-116.

McFeeters, B., Ryan, M.J., Schröder-Adams, C. et al. (2016) A new ornithomimid theropod from the Dinosaur Park Formation of Alberta,
Canada. Journal of Vertebrate Paleontology, 36, e1221415. Available at: https://doi.org/10.1080/02724634.2016.1221415.

Moreno, K., Carrano, M.T. and Snyder, R. (2007) Morphological changes in pedal phalanges through ornithopod dinosaur evolution: a biomechanical approach. Journal of Morphology, 268, 50-63.

Mosimann, J.E. and James, F.C. (1979) New statistical methods for allometry with application to Florida Red-winged Blackbirds. Evolution, 33, 444-459.

Mosto, M.C., Carril, J. and Picasso, M.B.J. (2013) The hindlimb myology of Milvago chimango (Polyborinae, Falconidae). Journal of Morphology, 274, 1191-1201.

Mudroch, A., Richter, U., Joger, U. et al. (2011) Didactyl tracks of paravian theropods (Maniraptora) from the ?Middle Jurassic of Africa. PLoS ONE, 6, e14642. Available at: https://doi.org/10.1371/journ al.pone.0014642.

Norell, M.A., Clark, J.M., Turner, A.H. et al. (2006) A new dromaeosaurid theropod from Ukhaa Tolgod (Ömnögov, Mongolia). American Museum Novitates, 3545, 1-51.

Norell, M.A. and Makovicky, P.J. (1997) Important features of the dromaeosaur skeleton: information of a new specimen. American Museum Novitates, 3215, 1-28.

Norell, M.A. and Makovicky, P.J. (1999) Important features of the dromaeosaur skeleton II: information from newly collected specimens of Velociraptor mongoliensis. American Museum Novitates, 3282, 1-45.

Novas, F.E., Brissón Egli, F., Agnolín, F.L. et al. (2018) Postcranial osteology of a new specimen of Buitreraptor gonzalezorum (Theropoda, Unenlagiidae). Cretaceous Res, 83, 127-167. Available at: https://doi. org/10.1016/j.cretres.2017.06.003.

Novas, F.E. and Pol, D. (2005) New evidence on deinonychosaurian dinosaurs from the Late Cretaceous of Patagonia. Nature, 433, 858-861. Available at: https://doi.org/10.1038/nature03285.

Novas, F.E., Pol, D., Canale, J.I. et al. (2009) A bizarre Cretaceous theropod dinosaur from Patagonia and the evolution of Gondwanan dromaeosaurids. Proceedings of the Royal Society B: Biological Sciences, 276, 1101-1107.

Novas, F.E. and Puerta, P.F. (1997) New evidence concerning avian origins from the Late Cretaceous of Patagonia. Nature, 387, 390-392.

O'Connor, J., Zhou, Z. and Xu, X. (2011) Additional specimen of Microraptor provides unique evidence of dinosaurs preying on birds. Proceedings of the National Academy of Sciences of the United States of America, 108, 19662-19665.

Osmólska, H. (1981) Coossified tarsometatarsi in theropod dinosaurs and their bearing on the problem of bird origins. Palaeontol Polonica, 42, 79-95.

Osmólska, H., Roniewicz, E. and Barsbold, R. (1972) A new dinosaur, Gallimimus bullatus n. gen., n. sp. (Ornithomimidae) from the Upper Cretaceous of Mongolia. Palaeontol Polonica, 27, 103-143.

Ostrom, J.H. (1969) Osteology of Deinonychus antirrhopus, an unusual theropod from the Lower Cretaceous of Montana. Bulletin of the Peabody Museum of Natural History, 30, 1-165.

Ostrom, J.H. (1976) On a new specimen of the Lower Cretaceous theropod dinosaur Deinonychus antirrhopus. Breviora, 439, 1-21.

Paul, G.S. (1998) Limb design, function and running performance in ostrich-mimics and tyrannosaurs. Gaia, 15, 257-270.

Paradis, E., Claude, J. and Strimmer, K. (2004) APE: analyses of phylogenetics and evolution in R language. Bioinformatics, 20, 289-290.

Pei, R., Li, Q., Meng, Q. et al. (2014) A new specimen of Microraptor (Theropoda: Dromaeosauridae) from the Lower Cretaceous of western Liaoning, China. American Museum Novitates, 3821, 1-28. Available at: https://doi.org/10.1206/3821.1.

Picasso, M.B.J. (2010) The hindlimb muscles of Rhea Americana (Aves, Palaeognathae, Rheidae). Anatomia Histologia and Embryologia, 39, 462-472.

Pike, A.V.L. and Maitland, D.P. (2004) Scaling of bird claws. Journal of Zoology, 262, 73-81. 
Pol, D. and Apesteguía, S. (2005) New Araripesuchus remains from the early Late Cretaceous (Cenomanian-Turonian) of Patagonia. American Museum Novitates, 3490, 1-38.

Porfiri, J.D., Calvo, J.O. and Dos Santos, D. (2011) A new small deinonychosaur (Dinosauria: Theropoda) from the Late Cretaceous of Patagonia, Argentina. Anais da Academia Brasileira de Ciências, 83, 109-116.

Portugal, S.J., Murn, C.P., Sparkes, E.L. et al. (2016) The fast and forceful kicking strike of the secretary bird. Current Biology, 26, R58-R59.

Revell, L.J. (2012) Phytools: An R package for phylogenetic comparative biology (and other things). Methods in Ecology and Evolution, 3, 217-223.

Rougier, G.W., Apesteguía, S. and Gaetano, L.C. (2011) Highly specialized mammalian skulls from the Late Cretaceous of South America. Nature, 479, 98-102.

Russell, D.A. (1972) Ostrich dinosaurs from the Late Cretaceous of Western Canada. Canadian Journal of Earth Sciences, 9, 375-402.

Russell, D. and Dong, Z. (1993) A nearly complete skeleton of a new troodontid dinosaur from the Early Cretaceous of the Ordos Basin, Inner Mongolia, People's Republic of China. Canadian Journal of Earth Sciences, 30, 2163-2173.

Senter, P. (2009) Pedal function in deinonychosaurs (Dinosauria: Theropoda): a comparative study. Bulletin of Gunma Museum of Natural History, 13, 1-14.

Sinclair, W. and Farr, M. (1932) Aves of the Santa Cruz Beds. In: Scott, W. (Ed.) Reports of the Princeton University Expeditions to Patagonia (18961899). Vol. 7, Princeton: Princeton University Press, pp. 157-191.

Snively, E. and Russell, A.P. (2002) The tyrannosaurid metatarsus: bone strain and inferred ligament function. Senck Leth, 81, 73-80.

Snively, E. and Russell, A.P. (2003) Kinematic model of tyrannosaurid (Dinosauria: Theropoda) arctometatarsus function. Journal of Morphology, 255, 215-227.

Snively, E., Russell, A.P. and Powell, G.L. (2004) Evolutionary morphology of the coelurosaurian arctometatarsus: descriptive, morphometric and phylogenetic approaches. Zoological Journal of the Linnean Society, 142, 525-553.

Spicer, G.S. and Dunipace, L. (2004) Molecular phylogeny of songbirds (Passeriformes) inferred from mitochondrial 16S ribosomal RNA gene sequences. Molecular Phylogenetics and Evolution, 30, 325-335.

Stein, B.R. and Casinos, A. (1997) What is a cursorial mammal? Journal of Zoology, 242, 185-192.

Tsogtbaatar, C., Kobayashi, Y., Tsogtbaatar, K. et al. (2017) First Ornithomimid (Theropoda, Ornithomimosauria) from the Upper Cretaceous Djadokhta Formation of Tögrögiin Shiree, Mongolia. Scientific Reports, 7, 5835. Available at: https://doi.org/10.1038/ s41598-017-05272-6.

Turner, A.H., Makovicky, P.J. and Norell, M.A. (2012) A review of dromaeosaurids systematics and paravian phylogeny. Bulletin of the American Museum of Natural History, 371, 1-206.

Turner, A.H., Pol, D., Clarke, J.A. et al. (2007) A basal dromaeosaurid and size evolution preceding avian flight. Science, 317, 1378-1381.

Turner, A.H., Pol, D. and Norell, M.A. (2011) Anatomy of Mahakala omnogovae (Theropoda: Dromaeosauridae), Tögrögiin Shiree, Mongolia. American Museum Novitates, 3722, 1-66. Available at: https://doi. org/10.1206/3722.2.

Vanden Berge, J.C., Zweers, G.A. et al. (1993) Myology. In: Baumel, J.J., King, A.S. and Breazile, J.E. (Eds.) Handbook of Avian Anatomy: Nomina Anatomica Avium, Vol. 23. Cambridge: Publications of the Nuttall Ornithological Club, pp. 45-132.

Vickers-Rich, P., Chiappe, L.M. and Kurzanov, S. (2002) The enigmatic birdlike dinosaur Avimimus portentosus: comments and pictorial atlas. In: Chiappe, L.M. and Witmer, L.M. (Eds.) Mesozoic Birds: Above the Heads of Dinosaurs. Berkeley: University of California Press, pp. 65-86.

Ward, A.B., Weigl, P.D. and Conroy, R.M. (2002) Functional morphology of raptor hindlimbs: implications for resource partitioning. The Auk, 119, 1052-1063.
White, M.A. (2009) The subarctometatarsus: intermediate metatarsus architecture demonstrating the evolution of the arctometatarsus and advanced agility in theropod dinosaurs. Alcheringa, 33, 1-21.

Wilson, M.C. and Currie, P.J. (1985) Stenonychosaurus inequalis (Saurischia: Theropoda) from the Judith River Formation of Alberta: new findings on metatarsal structure. Canadian Journal of Earth Sciences, 22, 1813-1817.

Wink, M., El-Sayed, A.-A., Sauer-Gürth, H. et al. (2009) Molecular phylogeny of owls (Strigiformes) inferred from DNA sequences of the mitochondrial cytochrome $b$ and the nuclear RAG-1 gene. Ardea, 97, 581-591.

Wu, L., Sun, Y., Li, J. et al. (2015) A phylogeny of the Passerida (Aves: Passeriformes) based on mitochondrial $12 \mathrm{~S}$ ribosomal RNA gene. Avian Research, 6, 1-8. Available at: https://doi.org/10.1186/ s40657-015-0010-5.

Xing, L.D., Harris, J.D., Sun, D.-H. et al. (2009) The earliest known deinonychosaur tracks from the Jurassic-Cretaceous boundary in Hebei Province, China. Acta Palaeontologica Sinica, 48, 662-671.

Xing, L., Persons, W.S. IV, Bell, P.R. et al. (2013) Piscivory in the feathered dinosaur Microraptor. Evolution, 67, 2441-2445.

Xu, X. (2002) Deinonychosaurian fossils from the Jehol Group of Western Liaoning and the coelurosaurian evolution. PhD Thesis, The Chinese Academy of Sciences, Beijing, 325 pp.

Xu, X., Choiniere, J.N., Pittman, M. et al. (2010) A new dromaeosaurid (Dinosauria: Theropoda) from the Upper Cretaceous Wulansuhai Formation of Inner Mongolia, China. Zootaxa, 2403, 1-9.

Xu, X., Choiniere, J.N., Tan, Q. et al. (2018) Two early cretaceous fossils document transitional stages in alvarezsaurian dinosaur evolution. Current Biology, 28, 2853-2860. Available at: https://doi. org/10.1016/j.cub.2018.07.057.

$\mathrm{Xu}, \mathrm{X}$. and Norell, M.A. (2004) A new troodontid from China with avian-like sleeping posture. Nature, 431, 838-841.

Xu, X., Norell, M.A., Wang, X.L. et al. (2002) A basal troodontid from the Early Cretaceous of China. Nature, 415, 780-784.

Xu, X. and Qin, Z.-C. (2017) A new tiny dromaeosaurid dinosaur from the Lower Cretaceous Jehol Group of western Liaoning and niche differentiation among the Jehol dromaeosaurids. Vertebrat PalAsiatic, 55, 129-144.

Xu, X., Sullivan, C., Pittman, M. et al. (2011) A monodactyl non-avian dinosaur and the complex evolution of the alvarezsauroid hand. Proceedings of the National Academy of Sciences of the United States of America, 108, 2338-2342.

Xu, X., Upchurch, P., Ma, Q. et al. (2013) Osteology of the Late Cretaceous alvarezsauroid Linhenykus monodactylus from China and comments on alvarezsauroid biogeography. Acta Palaeontologica Polonica, 58, 25-46.

Xu, X., Currie, P., Pittman, M. et al. (2017) Mosaic evolution in an asymmetrically feathered troodontid dinosaur with transitional features. Nature Communications, 8, 14972. Available at: https://doi. org/10.1038/ncomms14972.

Xu, X. and Wang, X.-L. (2000) Troodontid-like pes in the dromaeosaurid Sinornithosaurus. Korea Spec Publ, 4, 179-188.

Xu, X., Zhao, Q., Norell, M. et al. (2008) A new feathered maniraptoran dinosaur fossil that fills a morphological gap in avian origin. Chinese Sci Bull, 54, 430-435. Available at: https://doi.org/10.1007/ s11434-009-0009-6.

Xu, X., Zhou, Z. and Wang, X. (2000) The smallest known non-avian theropod dinosaur. Nature, 408, 705-708. Available at: https://doi. org/10.1038/35047056.

Xu, X., Zhou, Z., Wang, X. et al. (2003) Four-winged dinosaurs from China. Nature, 421, 335-340.

Zanno, L.E., Varricchio, D.J., O'Connor, P.M., et al. (2011) A New Troodontid Theropod, Talos sampsoni gen. et sp. nov., from the Upper Cretaceous Western Interior Basin of North America. PLoS ONE, 6(9), e24487. Available at: https://doi.org/10.1371/journal.pone.0024487.

Zeffer, A., Johansson, L.C. and Marmebro, A. (2003) Functional correlation between habitat use and leg morphology in birds (Aves). Biological Journal of the Linnean Society, 79, 461-484. 
Zhen, S., Li, J., Zhang, B. et al. (1994) Dinosaur and bird footprints from the Lower Cretaceous of Emei county, Sichuan. Memoirs of the Beijing Natural History Museum, 54, 105-120.

Zheng, X., Xu, X., You, H. et al. (2010) A short-armed dromaeosaurid from the Jehol Group of China with implications for early dromaeosaurid evolution. Proceedings of the Royal Society B: Biological Sciences, 277, 211-217. Available at: https://doi.org/10.1098/rspb.2009.1178.

Zhou, Z. and Farlow, J.O. (2001) Flight capability and habits of Confuciusornis. In: Gauthier, J. and Gall, L.F. (Eds.) New Perspectives on the Origin and Early Evolution of Birds: Proceedings of the International Symposium in Honor of John H. Ostrom. New Haven: Peabody Museum of Natural History, Yale University, pp. 237-254.

Zhou, Z., Zhang, F. and Li, Z. (2010) A new Lower Cretaceous bird from China and tooth reduction in early avian evolution. Proceedings of the Royal Society B: Biological Sciences, 277, 219-227. https://doi. org/10.1098/rspb.2009.0885.

\section{SUPPORTING INFORMATION}

Additional supporting information may be found online in the Supporting Information section.

How to cite this article: Gianechini FA, Ercoli MD, DíazMartínez I. Differential locomotor and predatory strategies of Gondwanan and derived Laurasian dromaeosaurids (Dinosauria, Theropoda, Paraves): Inferences from morphometric and comparative anatomical studies. J. Anat. 2020;00:1-26. https://doi.org/10.1111/joa.13153 